\title{
SUPERCONDUCTIVITY IN TITANIUM-BASED PNICTIDE OXIDE COMPOUNDS
}

\author{
BERND LORENZ* \\ Texas Center for Superconductivity and Department of Physics, University of Houston, \\ 3201 Cullen Blvd., Houston, Texas 77204-5002, USA \\ ARNOLD M. GULOY \\ Texas Center for Superconductivity and Department of Chemistry, University of Houston, \\ 3201 Cullen Blvd., Houston, Texas 77204-5002, USA \\ PAUL C. W. CHU \\ Texas Center for Superconductivity and Department of Physics, University of Houston, \\ 3201 Cullen Blvd., Houston, Texas 77204-5002, USA
}

\begin{abstract}
Superconductivity in a novel class of layered materials, Ti-based pnictide oxides, was recently discovered. These compounds have attracted interest since they combine features of copper oxide and iron pnictide superconductors. Here the transition metal (titanium) forms two-dimensional $\mathrm{Ti}_{2} \mathrm{O}$ layers (anti structure to the $\mathrm{CuO}_{2}$ planes), capped by pnictogen ions (similar to $\mathrm{Fe}_{2} \mathrm{As}_{2}$ layers). The pnictide oxide compounds show a spin or charge density wave phase which coexists with superconductivity in some members of the family. Unlike the cuprates, but similar to iron pnictides, the parent compounds of pnictide oxides are metals with specific nesting properties of the Fermi surface which leads to the density wave instability. The nature of the superconductivity, coexisting with the density wave order, and the possible competition or mutual interaction between both states is one of the central questions of recent studies. This short review summarizes the current knowledge from an experimental as well as theoretical point of view and discusses some of the open questions and possible future developments.
\end{abstract}

Keywords: pnictide oxides; density wave order; superconductivity.

\section{Introduction}

Superconductivity in transition metal oxides (copper oxides or cuprates), pnictides (iron arsenides), or chalcogenides (FeSe, $\mathrm{KFe}_{2} \mathrm{Se}_{2}$ ) have attracted increasing attention recently, not only because of the extraordinary high transition temperatures achieved in some systems, but also because of the proximity of those systems to longrange magnetic orders in form of antiferromagnetism (cuprates) 112 or spin density waves (pnictides)!34516 As a consequence, "unconventional" pairing symmetries (d-wave in cuprates, $\mathrm{s}^{+/-}$in pnictides) mediated by spin fluctuations have been proposed to explain the superconducting properties of these systems. ${ }^{7}$ The magnetic

\footnotetext{
*blorenz@uh.edu
} 
fluctuations play a significant role ${ }^{8}$ and evidence for a magnetic quantum critical point, hidden in the superconducting dome, was found in several pnictides.9/10/11 Structurally, cuprates and pnictides have in common the layered structure with active superconducting layers $\left(\mathrm{CuO}_{2}\right.$ in cuprates and $\mathrm{FeAs}$ in pnictides) separated by charge reservoir blocks.

Superconductivity commonly arises through charge doping from a nonsuperconducting parent compound which, in most cuprates and pnictides, exhibits magnetic order in the ground state. Charge doping can be achieved by either varying the oxygen content (in cuprates the oxygen content can be controlled by synthesis and annealing, in pnictides oxygen can be replaced by fluorine or hydrogen) or by replacing cations with ions of different valency (for example, $\mathrm{Sr}$ for $\mathrm{La}$ in $\mathrm{La}_{2} \mathrm{CuO}_{4}$ or $\mathrm{K}$ for $\mathrm{Ba}$ in $\mathrm{BaFe}_{2} \mathrm{As}_{2}$ ). However, there are exemptions from the rule. LiFeAs was found to be a stoichiometric self-doped superconductor which does not need additional doping 12 Isovalent doping of phosphorous for arsenic 13 as well as hydrostatic pressure 14 have also been shown to induce superconductivity in the parent compounds of some pnictides.

In view of the exciting superconducting properties of layered cuprates and pnictides as well as the wealth of interesting physical phenomena that originate from the strong correlations between magnetism and superconductivity, various attempts have been made to search for other layered transition metal oxides/pnictides where superconductivity could be established near magnetic or other instabilities. One of the compound families with interesting magnetic and electronic properties are the Ti-based layered pnictide oxide systems of the general formula $A \mathrm{Ti}_{2} P n_{2} \mathrm{O}$, with $A=\mathrm{Na}_{2}, \mathrm{Ba},(\mathrm{SrF})_{2}$, etc. and $P n=\mathrm{As}, \mathrm{Sb}, \mathrm{Bi}$. The first synthesis of $\mathrm{Na}_{2} \mathrm{Ti}_{2} \mathrm{As}_{2} \mathrm{O}$ and $\mathrm{Na}_{2} \mathrm{Ti}_{2} \mathrm{Sb}_{2} \mathrm{O}$ by Adam and Schuster $\frac{15}{15} 1990$ revealed an interesting anti-K ${ }_{2} \mathrm{NiF}_{4}$ structure, the existence of magnetic interactions in the $\mathrm{Ti}_{2} \mathrm{O}$ layers resulting in a magnetic transition, but no indication of superconductivity was found $16[17$ These materials are members of a broader pnictide oxide class of compounds the structure and properties of which have been discusses about two decades ago. 18 The search for superconductivity in pnictide oxides was not successful until very recently where superconductivity was discovered in $\mathrm{BaTi}_{2} \mathrm{Sb}_{2} \mathrm{O}$ and $\mathrm{Ba}_{1-x} \mathrm{Na}_{x} \mathrm{Ti}_{2} \mathrm{Sb}_{2} \mathrm{O}{ }^{19} 20$ The existence of a superconducting state in pnictide oxides at low temperatures is of particular interest since superconductivity is preceded by a density wave transition at about $50 \mathrm{~K}$ and the possible coexistence and mutual interaction of both orders has inspired more theoretical and experimental work.

In the following sections we present a brief review of the state of the art of synthesis, structure, physical properties, and superconductivity research of Ti-based pnictide oxide compounds. 


\section{Synthesis and Structure}

\section{1. $\mathrm{Na}_{2} \mathrm{Ti}_{2} \mathrm{Pn}_{2} \mathrm{O}$}

The synthesis of $\mathrm{Na}_{2} \mathrm{Ti}_{2} \mathrm{Pn}_{2} \mathrm{O}(P n=\mathrm{As}, \mathrm{Sb})$ was first described by Adam and Schuster 15 The solid state synthesis was achieved by mixing the precursor compounds $\mathrm{Na}_{2} \mathrm{O}$ and TiAs (TiSb) at a ratio of 1:2 and annealing in Argon atmosphere for several hours at $800^{\circ} \mathrm{C}$ to $900^{\circ} \mathrm{C}$. The resulting synthesis products, $\mathrm{Na}_{2} \mathrm{Ti}_{2} \mathrm{As}_{2} \mathrm{O}$ and $\mathrm{Na}_{2} \mathrm{Ti}_{2} \mathrm{Sb}_{2} \mathrm{O}$, crystallize in the tetragonal structure, space group $\mathrm{I} / \mathrm{mmm}$ (No. 139). The material is unstable when exposed to air or moisture ${ }^{15}$ Similar routes to synthesize $\mathrm{Na}_{2} \mathrm{Ti}_{2} \mathrm{Sb}_{2} \mathrm{O}$ have been chosen by reacting stoichiometric amounts of $\mathrm{Na}_{2} \mathrm{O}, \mathrm{Ti}$, and $\mathrm{Sb}$ powder in sealed Ta tubes at a temperature of $1000^{\circ} \mathrm{C}$ for three days ${ }^{2122}$ Liu et al. used carefully prepared $\mathrm{NaPn}$ powder mixed with powders of $\mathrm{TiO}_{2}$ and $\mathrm{Ti}$ in the stoichiometric ratio to synthesize $\mathrm{Na}_{2} \mathrm{Ti}_{2} \mathrm{Pn}_{2} \mathrm{O}$ through sintering at $800^{\circ} \mathrm{C}$ in argon atmosphere for 50 hours $\frac{23}{23}$ In order to avoid contamination, all preparations had to be carried out in a glove box filled with high purity argon gas.

Single crystals of $\mathrm{Na}_{2} \mathrm{Ti}_{2} \mathrm{Sb}_{2} \mathrm{O}$ can be grown by a NaSb flux method, as described in detail by Ozawa and Kauzlarich! ${ }^{24}$ The polycrystalline sample of $\mathrm{Na}_{2} \mathrm{Ti}_{2} \mathrm{Sb}_{2} \mathrm{O}$, prepared by solid state reaction, and the NaSb flux were placed in a Ta tube enclosed in a fused silica ampoule. Crystal growth was achieved in a vertical furnace. The best crystals were obtained at a reaction temperature of $1100^{\circ} \mathrm{C}$, slow cooling at a rate of 5 to $10^{\circ} \mathrm{C} / \mathrm{h}$, and quenching from $550^{\circ} \mathrm{C}$. This procedure yielded plate-like single crystals of several millimeters in size. Very recently, the flux method was also employed by Shi et al. to grow similarly sized single crystals of $\mathrm{Na}_{2} \mathrm{Ti}_{2} \mathrm{As}_{2} \mathrm{O}$ and $\mathrm{Na}_{2} \mathrm{Ti}_{2} \mathrm{Sb}_{2} \mathrm{O}$ from NaAs and $\mathrm{NaSb}$ flux, respectively 25

The structure type of $\mathrm{Na}_{2} \mathrm{Ti}_{2} \mathrm{Pn}_{2} \mathrm{O}$ is that of $\mathrm{Eu}_{4} \mathrm{As}_{2} \mathrm{O}\left(\right.$ anti- $\left.\mathrm{K}_{2} \mathrm{NiF}_{4}\right)$ with $\mathrm{Na}$ and $\mathrm{Ti}$ occupying the $\mathrm{Eu}(4 \mathrm{e})$ and $\mathrm{Eu}(4 \mathrm{c})$ sites, respectively. The tetragonal lattice of $\mathrm{Na}_{2} \mathrm{Ti}_{2} P n_{2} \mathrm{O}(a=4.070 \AA, c=15.288 \AA$ for $P n=\mathrm{As})$ is shown in Fig. 11a. The lattice parameters for $P n=\mathrm{Sb}$ are slightly larger, $a=4.144 \AA$ and $c=16.561 \AA 15$

The tetragonal structure of $\mathrm{Na}_{2} \mathrm{Ti}_{2} P n_{2} \mathrm{O}$ consists of different layers stacked along the $c$-axis. Titanium and oxygen ions form a square lattice with oxygen occupying the nodes and titanium ions located half way between two oxygens. The $P n$ ions are located in the center of the squares above and below the $\mathrm{Ti}_{2} \mathrm{O}$ lattice. Two $P n$ and four Ti form octahedra sharing corners only, as shown in the center of Fig. 1. The $\mathrm{Na}$ ions fill into the voids above and below the oxygen ions, forming a double layer which separates two neighboring $P n-\mathrm{Ti}_{2} \mathrm{O}-\mathrm{Pn}$ slabs. There are two variable parameters within the unit cell, the distance of the $P n$ ions above and below the $\mathrm{Ti}_{2} \mathrm{O}$ plane and the displacement of the $\mathrm{Na}$ ions from the center plane between two adjacent $P n-\mathrm{Ti}_{2} \mathrm{O}-\mathrm{Pn}$ slabs.

It is worth noting that the $\mathrm{Ti}_{2} \mathrm{O}$ square lattice is similar to the $\mathrm{CuO}_{2}$ lattice of the high-temperature superconducting cuprates, but the lattice positions of the transition metal and oxygen are interchanged (anti- $\mathrm{K}_{2} \mathrm{NiF}_{4}$ structure). Both square lattices are compared in Fig. 1 $\mathrm{b}$. The similarity of the planar structures has raised 
(a)

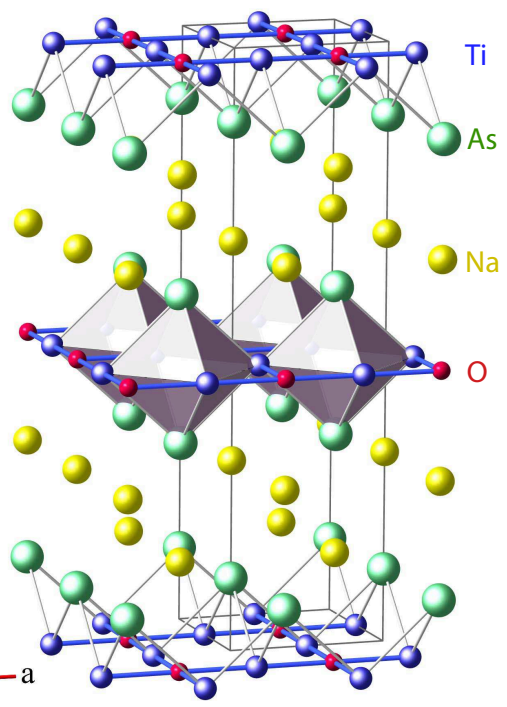

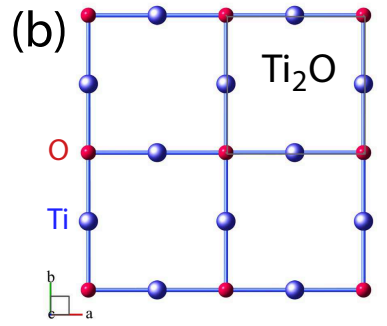

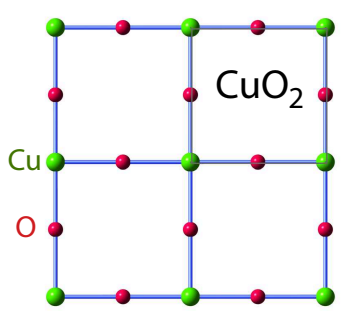

Fig. 1. (a) Structure of $\mathrm{Na}_{2} \mathrm{Ti}_{2} \mathrm{As}_{2} \mathrm{O}$. The main building blocks are the $\mathrm{Ti}_{2} \mathrm{O}$ plane capped by

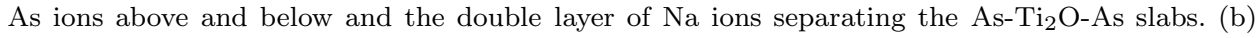
The $\mathrm{Ti}_{2} \mathrm{O}$ square lattice (top) compared with the $\mathrm{CuO}_{2}$ lattice (bottom) of the high-temperature superconducting cuprates.

the question if superconductivity could be induced into the $\mathrm{Ti}_{2} \mathrm{O}$ plane through proper doping. 16

\section{2. $\mathrm{BaTi}_{2} \mathrm{Pn}_{2} \mathrm{O}$}

The successful replacement of the $\left(\mathrm{Na}^{+}\right)_{2}$ double layer in $\mathrm{Na}_{2} \mathrm{Ti}_{2} \mathrm{As}_{2} \mathrm{O}$ by a single layer of divalent $\mathrm{Ba}^{2+}$ was first reported by Wang et al ${ }^{26}$ The synthesis resulted in a new layered pnictide oxide compound: $\mathrm{BaTi}_{2} \mathrm{As}_{2} \mathrm{O}$. The solid state synthesis was achieved by mixing the precursors $\mathrm{BaO}, \mathrm{Ti}$, and $\mathrm{As}$ in a stoichiometric ratio and annealing the mixture, wrapped in tantalum foil and sealed in quartz tubes, at $850^{\circ} \mathrm{C}$ for 40 hours. A polycrystalline sample of composition $\mathrm{BaTi}_{2} \mathrm{As}_{2} \mathrm{O}$ was obtained. Since $\mathrm{Ba}^{2+}$ substituting for two $\mathrm{Na}^{+}$does not significantly change the charge state of the $\mathrm{As}_{-} \mathrm{Ti}_{2} \mathrm{O}$-As block, a compound with similar physical properties was obtained.

The Sb-analogue, $\mathrm{BaTi}_{2} \mathrm{Sb}_{2} \mathrm{O}$, was synthesized by conventional solid state reaction, mixing the precursors $\mathrm{BaO}, \mathrm{Ti}$, and $\mathrm{Sb}$ at a ratio of 1:2:2. Two similar approaches have been reported: (i) Yajima et al 19 used tantalum foil to wrap the precursor material and sealed it in a quartz tube. The reaction was started by heating to $1000^{\circ} \mathrm{C}$ for 40 hours, followed by cooling to room temperature at a rate of $25^{\circ} \mathrm{C} / \mathrm{h}$. (ii) Doan et al 20 sealed the precursors in Nb tubes under argon gas and enclosed the tubes in sealed quartz ampoules. The samples were annealed for 3 days after heating $\left(2^{\circ} \mathrm{C} / \mathrm{min}\right)$ to $900^{\circ} \mathrm{C}$. Slow cooling $\left(1^{\circ} \mathrm{C} / \mathrm{min}\right)$ to $200^{\circ} \mathrm{C}$ and regrinding 


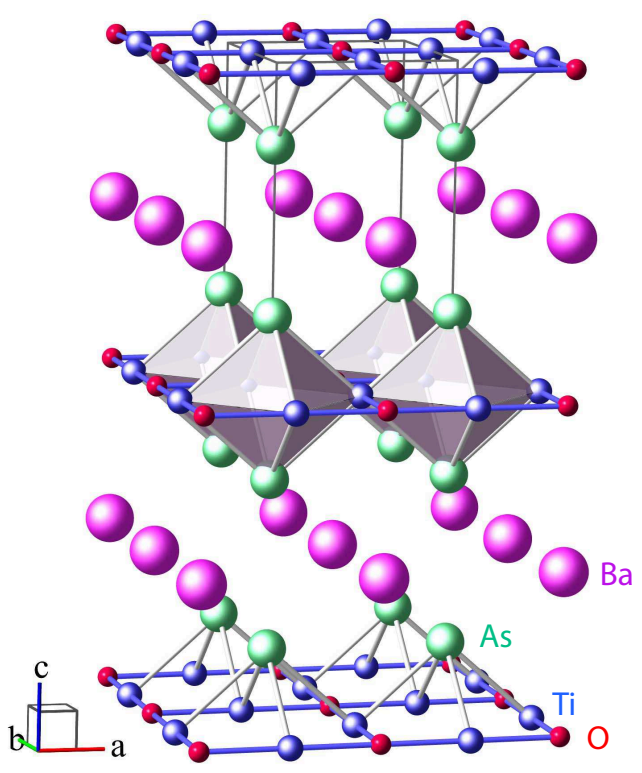

Fig. 2. Structure of $\mathrm{BaTi}_{2} \mathrm{As}_{2} \mathrm{O}$. Note that the $c$-axis is only half as long as in $\mathrm{Na}_{2} \mathrm{Ti}_{2} \mathrm{As}_{2} \mathrm{O}$.

and sintering at $900^{\circ} \mathrm{C}$ for another three days did ensure the homogeneity of the synthesis product.

The hole doped $\mathrm{Ba}_{1-x} \mathrm{Na}_{x} \mathrm{Ti}_{2} \mathrm{Sb}_{2} \mathrm{O}$ was successfully synthesized following a similar procedure using $\mathrm{BaO}, \mathrm{BaO}_{2}, \mathrm{Na}_{2} \mathrm{O}, \mathrm{Na}_{2} \mathrm{O}_{2}, \mathrm{Ti}$, and $\mathrm{Sb}$ mixed in stoichiometric amounts as precursor materials. $\frac{20}{2}$ Hole doping was also achieved using $\mathrm{K}$ or $\mathrm{Rb}$ to partially replace Ba. Pachmayr and Johrendt describe the synthesis of $\mathrm{Ba}_{1-x} \mathrm{~K}_{x} \mathrm{Ti}_{2} \mathrm{Sb}_{2} \mathrm{O}$ from different precursor materials, depending on the potassium content ${ }^{27}$ For $\mathrm{x}<0.5, \mathrm{Ba}, \mathrm{BaO}_{2}, \mathrm{~K}, \mathrm{Sb}$, and $\mathrm{Ti}$ were sealed in niobium tubes within silica ampoules (in argon) and slowly heated to $600^{\circ} \mathrm{C}$, held at this temperature for 15 hours, and cooled to room temperature. The reaction product was repeatedly ground, pelletized, and sintered at $900^{\circ} \mathrm{C}$ for 3 days, followed by slow cooling to $200^{\circ} \mathrm{C}$ to improve the chemical and structural homogeneity. For $\mathrm{x}>0.5, \mathrm{Ba}, \mathrm{K}, \mathrm{Sb}$, $\mathrm{Ti}$, and $\mathrm{TiO}_{2}$ have been used as precursors and the reaction and sintering conditions were slightly modified ${ }^{27}$ Von Rohr et al. synthesized $\mathrm{Ba}_{1-x} \mathrm{Rb}_{x} \mathrm{Ti}_{2} \mathrm{Sb}_{2} \mathrm{O}$ from a stoichiometric mixture of $\mathrm{BaO}, \mathrm{Rb}_{2} \mathrm{O}, \mathrm{Ti}, \mathrm{TiO}_{2}$, and $\mathrm{Sb} .28$ The precursor pellets were sealed in niobium tubes and sintered at $1000^{\circ} \mathrm{C}$ for 3 days. Regrinding and further sintering after the initial reaction for 24 hours at the same temperature ensured homogeneity of the final synthesis product.

Polycrystalline samples of $\mathrm{BaTi}_{2} \mathrm{Bi}_{2} \mathrm{O}$ as well as solid solutions of $\mathrm{BaTi}_{2}(\mathrm{As} / \mathrm{Sb})_{2} \mathrm{O}, \mathrm{BaTi}_{2}(\mathrm{Sb} / \mathrm{Bi})_{2} \mathrm{O}$, and $\mathrm{BaTi}_{2}(\mathrm{Sb} / \mathrm{Sn})_{2} \mathrm{O}$ have also been prepared by solid state reaction very recently $29|30| 31 \mid 32$

The $\mathrm{BaTi}_{2} \mathrm{Pn}_{2} \mathrm{O}$ compounds crystallize in the tetragonal structure with space 
group P4/mmm (No. 123). The structure, shown in Fig. 2, has the identical $\mathrm{Ti}_{2} \mathrm{O}$ square lattice capped above and below by $P n$ ions as $\mathrm{Na}_{2} \mathrm{Ti}_{2} P n_{2} \mathrm{O}$ (Fig. 1h). However, the stacking of the $P n-\mathrm{Ti}_{2} \mathrm{O}-P n$ slabs along the $c$-axis is different, every second slab is shifted along the $[1,1,0]$ direction so that two neighboring slabs are perfectly aligned along the $c$-direction. The $\mathrm{Ba}^{2+}$ ions then fit exactly halfway in between two $P n-\mathrm{Ti}_{2} \mathrm{O}-\mathrm{Pn}$ blocks forming a square lattice on their own. Thus the double layer of $\mathrm{Na}_{2}$ in $\mathrm{Na}_{2} \mathrm{Ti}_{2} \mathrm{Pn}_{2} \mathrm{O}$ is replaced by a plane of $\mathrm{Ba}$ ions in $\mathrm{BaTi}_{2} \mathrm{Pn}_{2} \mathrm{O}$. This results in a reduction of the $c$-axis and the unit cell volume by about $50 \%$, as shown in Fig. 2. The symmetry leaves only one adjustable parameter in the unit cell, the distance of the $P n$ ions from the $\mathrm{Ti}_{2} \mathrm{O}$ plane.

The lattice parameters of $\mathrm{BaTi}_{2} P n_{2} \mathrm{O}$ increase from $P n=\mathrm{As}(a=4.0456 \AA$, $c=7.2723 \AA)^{26}$ via $P n=\operatorname{Sb}(a=4.1196 \AA, c=8.0951 \AA){ }^{20}$ to $P n=\operatorname{Bi}(a=4.12316$ $\AA, c=8.3447 \AA)^{33}$ with the ionic size of the pnictogen, as expected. The lattice parameters of the solid solutions $\mathrm{BaTi}_{2}\left(\mathrm{As}_{1-x} \mathrm{Sb}_{x}\right)_{2} \mathrm{O}$ and $\mathrm{BaTi}_{2}\left(\mathrm{Sb}_{1-x} \mathrm{Bi}_{x}\right)_{2} \mathrm{O}$ change linearly with $\mathrm{x}$ following Vegard's law, indicating a homogeneous mixing of ions on the pnictogen site 31

\section{Physical properties of pnictide oxides $\mathrm{Na}_{2} \mathrm{Ti}_{2} \mathrm{Pn}_{2} \mathrm{O}$ and $\mathrm{BaTi}_{2} \mathrm{Pn}_{2} \mathrm{O}$}

The physical properties of pnictide oxide compounds are mainly determined by the charges and spins of the titanium $d$-orbitals and the hybridized pnictogen $p$-states. Thereby, the major contribution to the Fermi surface arises from Ti $d$-states with a sharp peak of the density of states near the Fermi energy $E_{F}, \underline{34}$ The simplified ionic picture with valencies of oxygen (2-), pnictogen (3-), Ba or $\mathrm{Na}_{2}(2+)$ leaves the valence state of $\mathrm{Ti}(3+)$ as $3 d^{1}$. The one $3 d$ electron of titanium is therefore largely responsible for the transport and magnetic properties of the compounds. The existence of $3 d^{1}$ electrons with spin $1 / 2$ at the Fermi energy may result in magnetic fluctuations through superexchange interactions involving the oxygen or pnictogen orbitals, as well as direct exchange between two Ti ions.

The first measurements of magnetic properties of $\mathrm{Na}_{2} \mathrm{Ti}_{2} \mathrm{Sb}_{2} \mathrm{O}$ by Adam and Schuster have indeed revealed an anomaly of the susceptibility near a critical temperature of $\mathrm{T}_{D W} \simeq 120 \mathrm{~K}{ }^{15}$ The exact nature of the transition, however, is still under discussion (see Section 4.4). The existence of a phase transition in $\mathrm{Na}_{2} \mathrm{Ti}_{2} \mathrm{Sb}_{2} \mathrm{O}$ was confirmed by Axtell et al. in revealing a spin-gap like behavior of the magnetic susceptibility. 21 The susceptibility shows a sharp drop below $114 \mathrm{~K}$ possibly indicating the opening of a spin gap in the magnetic excitation spectrum. At the transition temperature, the metallic resistivity displays a sharp increase with a subsequent decrease toward lower temperatures. The original results of Axtell et al. are shown in Fig. 3. Other physical quantities, e.g. thermoelectric power and heat

capacity, show clear anomalies at $\mathrm{T}_{D W} \cdot 23$ A large magnetoresistance effect of up to $40 \%$ was found at low temperatures and in fields up to 14 Tesla which hints for a coupling of the $3 d$ electrons to the external field. 

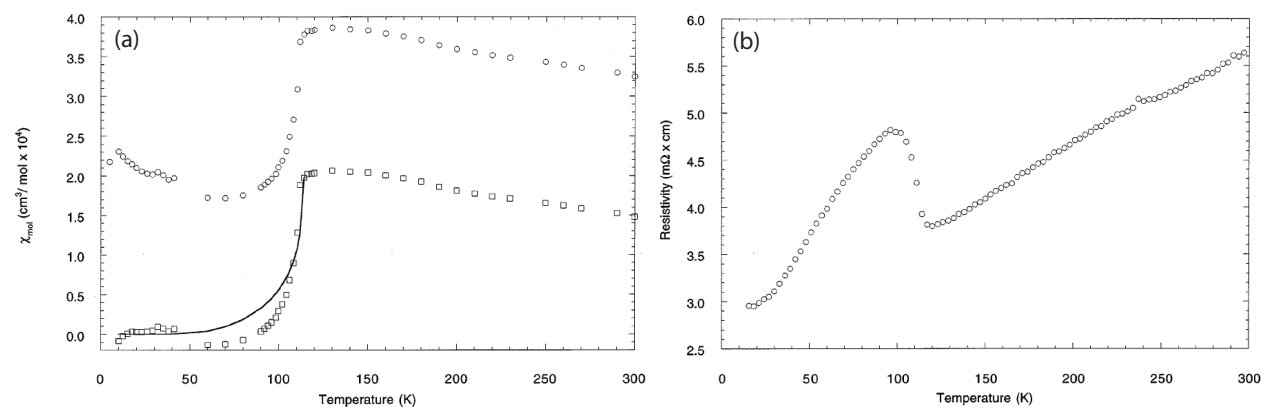

Fig. 3. (a) Magnetic susceptibility and (b) resistivity of $\mathrm{Na}_{2} \mathrm{Ti}_{2} \mathrm{Sb}_{2} \mathrm{O}$. The lower curve in (a) was obtained after subtracting a constant (van Vleck) and a Curie-like paramagnetic contribution from the original data. Reprinted with the publisher's permission from E. A. Axtell, III, et al. J. Solid State Chem. 134, 423 (1997).
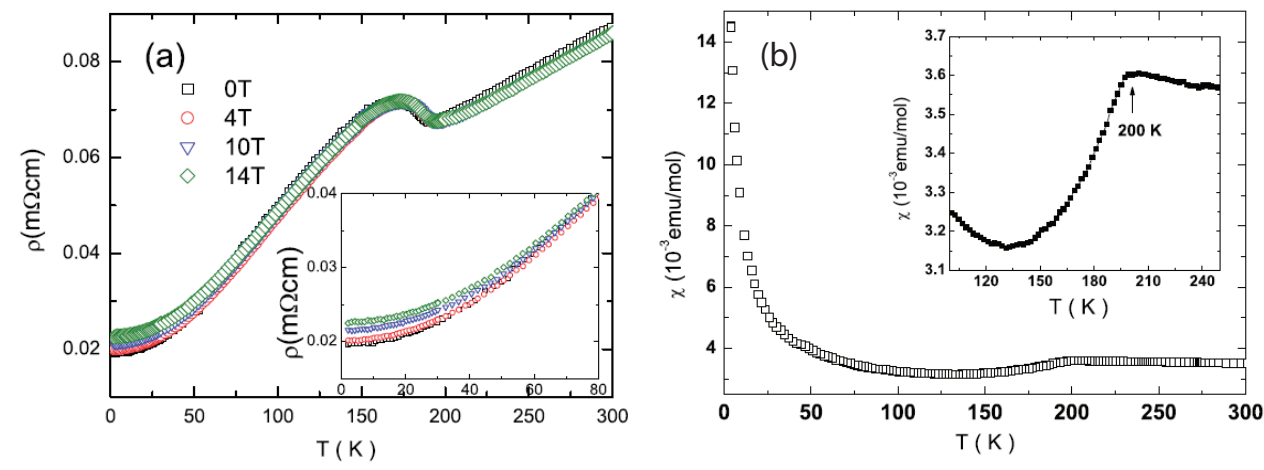

Fig. 4. (a) Resistivity and (b) magnetic susceptibility of $\mathrm{BaTi}_{2} \mathrm{As}_{2} \mathrm{O}$. The inset in (a) shows the magnetic field-effect at low temperatures on an enlarged scale. Reprinted with the publisher's permission from X. F. Wang, et al. J. Phys.: Condens. Matter 22, 075702 (2010).

The possible origin of the instability in $\mathrm{Na}_{2} \mathrm{Ti}_{2} \mathrm{Sb}_{2} \mathrm{O}$ was addressed by Pickett 34 based on first-principles calculations of the electronic structure (see also Section 5). The metallic character of $\mathrm{Na}_{2} \mathrm{Ti}_{2} \mathrm{Sb}_{2} \mathrm{O}$ was explained by a strong mixing of the $\mathrm{Ti} d$-states with the $p$-states of $\mathrm{Sb}$ and $\mathrm{O}$ and the direct $d$ - $d$ overlap. The Fermi surface, dominated by the delocalized $\mathrm{Ti} 3 d$ states, exhibits a nesting property which apparently leads to the observed instability at $\mathrm{T}_{D W}$. The low-temperature state could be a spin-density wave (SDW) or a charge-density wave (CDW) state, but the calculations did not allow to decide which order may be realized in $\mathrm{Na}_{2} \mathrm{Ti}_{2} \mathrm{Sb}_{2} \mathrm{O}$.

A similar drop of the magnetic susceptibility, although not as sharp, was found in $\mathrm{Na}_{2} \mathrm{Ti}_{2} \mathrm{As}_{2} \mathrm{O}$ at about $320 \mathrm{~K}, 22$ but a clear anomaly in the resistivity could not be resolved 23 The overall transport characteristics of $\mathrm{Na}_{2} \mathrm{Ti}_{2} \mathrm{As}_{2} \mathrm{O}$ shows a negative temperature coefficient, in contrast to the metallic behavior of $\mathrm{Na}_{2} \mathrm{Ti}_{2} \mathrm{Sb}_{2} \mathrm{O}$. The 

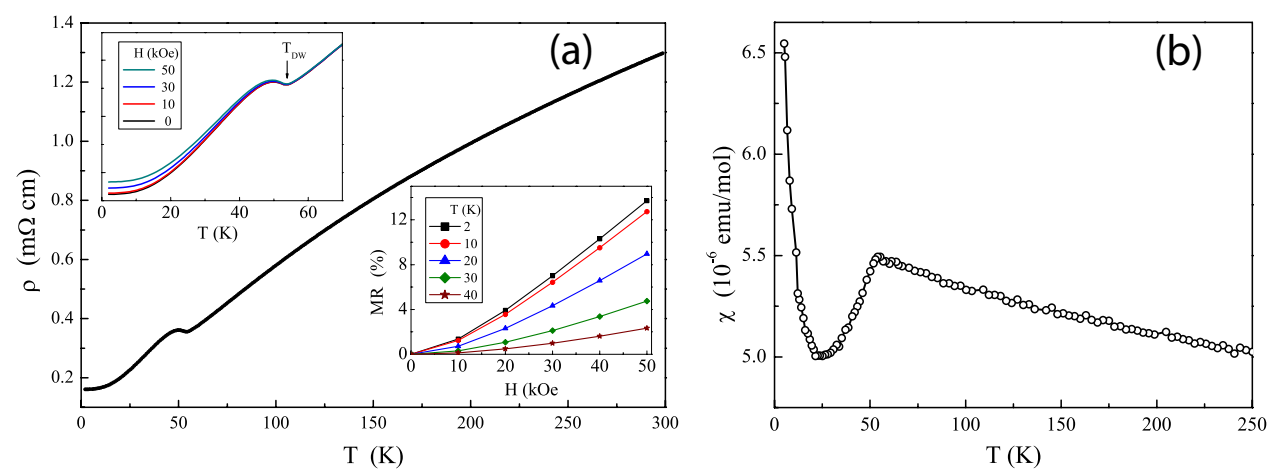

Fig. 5. (a) Resistivity and (b) magnetic susceptibility of $\mathrm{BaTi}_{2} \mathrm{Sb}_{2} \mathrm{O}$. The upper inset in (a) shows the magnetic field-effect at low temperatures on an enlarged scale. The lower inset displays the magnetoresistance at several constant temperatures.

significantly higher $\mathrm{T}_{D W}$ of $\mathrm{Na}_{2} \mathrm{Ti}_{2} \mathrm{As}_{2} \mathrm{O}$ shows that the pnictogen ion has a strong influence on the stability range of the density wave phase.

$\mathrm{BaTi}_{2} \mathrm{As}_{2} \mathrm{O}$, first synthesized by Wang et al. ${ }^{26}$ in 2010 , exhibits the density wave transition at $\mathrm{T}_{D W}=200 \mathrm{~K}$, significantly lower than $\mathrm{Na}_{2} \mathrm{Ti}_{2} \mathrm{As}_{2} \mathrm{O}$. A clear drop of the magnetic susceptibility and a sharp increase of the resistivity, followed by a metalliclike decrease to lower temperature, as well as a pronounced peak of the heat capacity signal the onset of the density wave order. Resistivity and magnetic susceptibility data from Ref. [26] are shown in Fig. 4. Attempts to induce superconductivity by charge doping into the $\mathrm{Ti}_{2} \mathrm{O}$ plane through substitution of barium by potassium or sodium as well as intercalation of lithium have not been successful. However, the density wave transition was shifted to lower temperature in the intercalated $\mathrm{Li}_{x} \mathrm{BaTi}_{2} \mathrm{As}_{2} \mathrm{O}$.

The question whether or not superconductivity can be induced in the Ti-based layered pnictide oxide compounds could be related to the stability of the density wave phase. If the spin or charge ordered states compete with superconductivity, the suppression of the SDW/CDW phase should be in favor of a superconducting state. Comparing $\mathrm{T}_{D W}$ of $\mathrm{Na}_{2} \mathrm{Ti}_{2} P n_{2} \mathrm{O}$ for $P n=\mathrm{As}$ and $\mathrm{Pn}=\mathrm{Sb}$, it becomes obvious that the replacement of As by $\mathrm{Sb}$ reduces the critical temperature significantly, namely from $320 \mathrm{~K}(\mathrm{As})$ to $114 \mathrm{~K}(\mathrm{Sb})$. On the other hand, the $T_{D W}$ of $\mathrm{BaTi}_{2} \mathrm{As}_{2} \mathrm{O}(200$ $\mathrm{K})$ is also much smaller than that of $\mathrm{Na}_{2} \mathrm{Ti}_{2} \mathrm{As}_{2} \mathrm{O}(320 \mathrm{~K})$. The replacement of As by $\mathrm{Sb}$ or $\mathrm{Bi}$ in $\mathrm{BaTi}_{2} \mathrm{As}_{2} \mathrm{O}$ could further reduce or completely suppress the density wave state.

The physical properties of $\mathrm{BaTi}_{2} \mathrm{Sb}_{2} \mathrm{O}$, first synthesized in 2012, 1920 indeed show the decrease of $\mathrm{T}_{D W}$ to $54 \mathrm{~K}$. Resistivity and magnetic susceptibility data for $\mathrm{BaTi}_{2} \mathrm{Sb}_{2} \mathrm{O}$ are shown in Fig. 5 . The resistivity exhibits a hump-like feature with a sharp increase at $\mathrm{T}_{D W}$ and a large magnetoresistance effect at lower temperatures, as shown in the upper inset of Fig. $5 \mathrm{~b}$, similar to the results for $\mathrm{BaTi}_{2} \mathrm{As}_{2} \mathrm{O}$ (Fig. 4a). The magnitude of the magnetoresistance at $50 \mathrm{kOe}$ exceeds the one observed 

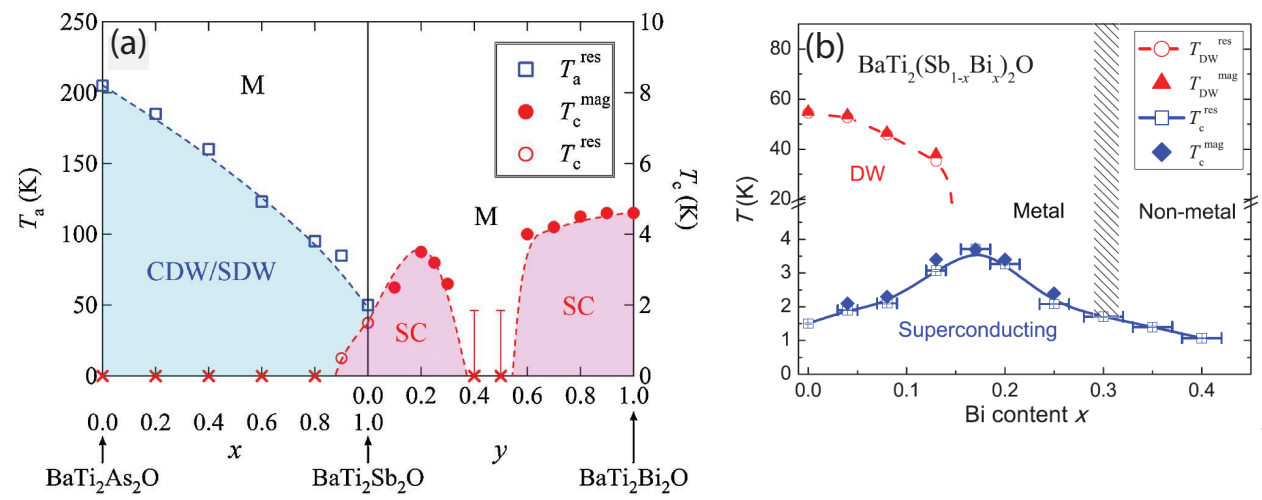

Fig. 6. (a) Phase diagram of $\mathrm{BaTi}_{2}\left(\mathrm{As}_{1-x} \mathrm{Sb}_{x}\right)_{2} \mathrm{O}$ (left half) and $\mathrm{BaTi}_{2}\left(\mathrm{Sb}_{1-x} \mathrm{Bi}_{x}\right)_{2} \mathrm{O}$ (right half). Reprinted with the publisher's permission from T. Yajima et al., J. Phys. Soc. Jpn. 82, 033705 (2013). (b) Phase diagram of $\mathrm{BaTi}_{2}\left(\mathrm{Sb}_{1-x} \mathrm{Bi}_{x}\right)_{2} \mathrm{O}$ in the range of low substitution, $\mathrm{x}<0.4$. Note the further reduction of $\mathrm{T}_{D W}$ upon Bi substitution. Reprinted with the publisher's permission from H.-F. Zhai et al., Phys. Rev. B 87, 100502(R) (2013).

in the As analogue significantly! $\frac{26}{2}$ The percentage increase, $(\rho(H)-\rho(0)) / \rho(0)$, at $2 \mathrm{~K}$ and $50 \mathrm{kOe}$ reaches $14 \%$. The density wave transition in $\mathrm{BaTi}_{2} \mathrm{Sb}_{2} \mathrm{O}$ is also revealed by a sharp drop of the magnetic susceptibility (Fig. 5 b).

It is obvious that the critical temperature of the density wave phase is significantly lower in $\mathrm{BaTi}_{2} \mathrm{Pn}_{2} \mathrm{O}$ and it is further reduced by replacing arsenic with antimony. It should be noted that this phase is completely absent at all temperatures in $\mathrm{BaTi}_{2} \mathrm{Bi}_{2} \mathrm{O} \stackrel{31}{\mathrm{~A}}$ systematic decrease of $\mathrm{T}_{D W}$ in $\mathrm{BaTi}_{2}\left(\mathrm{As}_{1-x} \mathrm{Sb}_{x}\right)_{2} \mathrm{O}$ from $200 \mathrm{~K}$ to $54 \mathrm{~K}$ and in $\mathrm{BaTi}_{2}\left(\mathrm{Sb}_{1-x} \mathrm{Bi}_{x}\right)_{2} \mathrm{O}$ from $54 \mathrm{~K}$ to zero temperature prove the suppression of the DW phase with increasing (average) size of the pnictogen ion. 29131 The phase diagrams for $\mathrm{BaTi}_{2}\left(\mathrm{As}_{1-x} \mathrm{Sb}_{x}\right)_{2} \mathrm{O}$ and $\mathrm{BaTi}_{2}\left(\mathrm{Sb}_{1-x} \mathrm{Bi}_{x}\right)_{2} \mathrm{O}$ are shown in Fig. [6a and Fig. 6b, respectively. The extrapolation of $\mathrm{T}_{D W}$ to zero temperature yields a critical value of the $B i$ content between $\mathrm{x}=0.15$ and $\mathrm{x}=0.2$.

\section{Superconductivity in pnictide oxide compopunds}

\subsection{Hole-doped $\mathrm{BaTi}_{2} \mathrm{Sb}_{2} \mathrm{O}$}

Superconductivity in the pnictide oxides was discovered simultaneously in $\mathrm{BaTi}_{2} \mathrm{Sb}_{2} \mathrm{O}$ with a critical temperature of $\mathrm{T}_{c}=1.2 \mathrm{~K} 19$ and in the sodium substituted $\mathrm{Ba}_{1-x} \mathrm{Na}_{x} \mathrm{Ti}_{2} \mathrm{Sb}_{2} \mathrm{O}$ with $\mathrm{T}_{c}$ up to $5.5 \mathrm{~K} \cdot 20$ The bulk nature of the superconducting state in $\mathrm{BaTi}_{2} \mathrm{Sb}_{2} \mathrm{O}$ is proven by a significant magnetic shielding signal and a pronounced peak of the heat capacity, as shown in Figs. $7 \mathrm{a}$ and $7 \mathrm{~b}$, respectively. The drop of the resistivity to zero confirms the existence of a superconducting phase below $1.2 \mathrm{~K}$.

Replacing $\mathrm{Ba}$ by $\mathrm{Na}$ removes electrons from the active layer, i.e. Na substitution results in hole doping of the $\mathrm{Ti}_{2} \mathrm{O}$ plane. The synthesis of $\mathrm{Ba}_{1-x} \mathrm{Na}_{x} \mathrm{Ti}_{2} \mathrm{Sb}_{2} \mathrm{O}$ was 

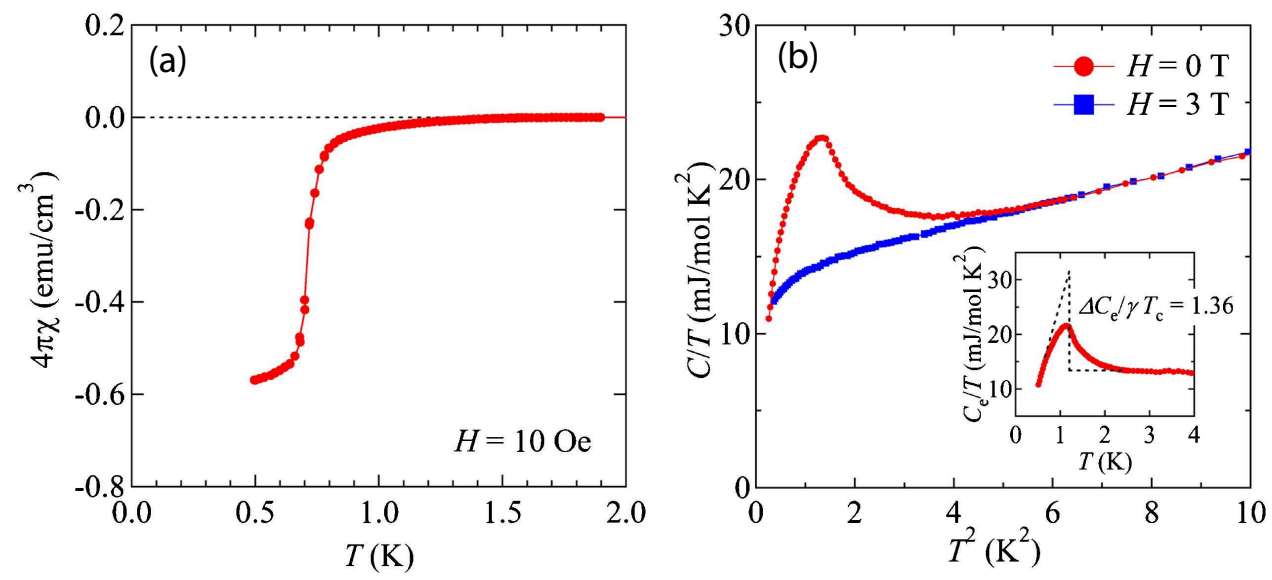

Fig. 7. (a) Superconducting shielding signal and (b) heat capacity of $\mathrm{BaTi}_{2} \mathrm{Sb}_{2} \mathrm{O}$. Reprinted with the publisher's permission from T. Yajima et al., J. Phys. Soc. Jpn. 81, 103706 (2012).
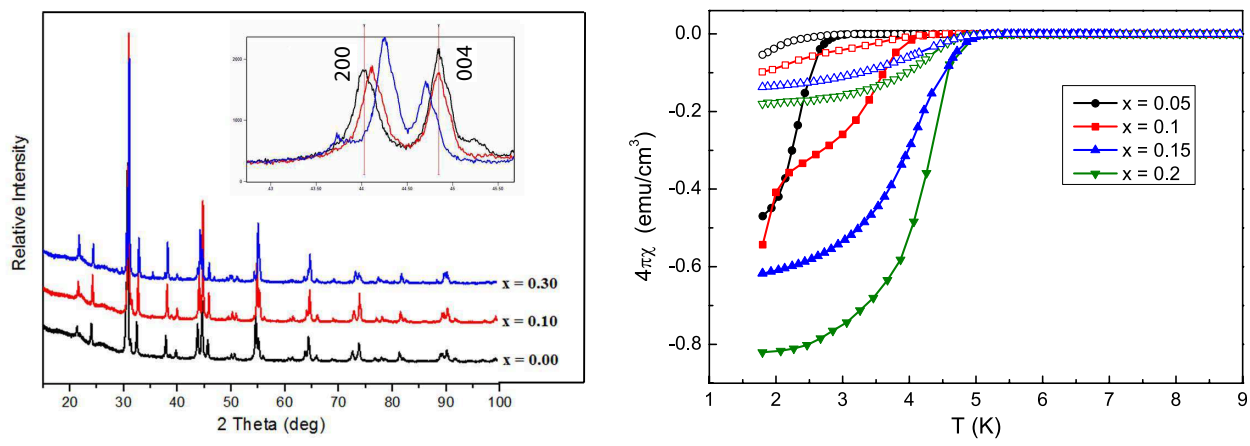

Fig. 8. (a) Selected X-ray spectra of hole-doped $\mathrm{Ba}_{1-x} \mathrm{Na}_{x} \mathrm{Ti}_{2} \mathrm{Sb}_{2} \mathrm{O}$. (b) Low-temperature magnetic susceptibility of $\mathrm{Ba}_{1-x} \mathrm{Na}_{x} \mathrm{Ti}_{2} \mathrm{Sb}_{2} \mathrm{O}$ measured in 10 Oe applied field. Bold symbols: Shielding signal (zero field cooled), Open symbols: Meissner signal (field cooled).

successful for $\mathrm{x} \leq 0.35$. X-ray spectra for $\mathrm{x}=0,0.1,0.3$ are shown in Fig. 8 a. The systematic shift of the [200] and [004] peak positions, shown in the inset, indicate that the $\mathrm{Na}$ ions dope into the $\mathrm{Ba}$ positions. The solubility limit for $\mathrm{Na}$ in the $\mathrm{P} 4 / \mathrm{mmm}$ structure was found at about $35 \%$. Magnetic susceptibility data in Fig. 8b prove the existence of superconductivity in $\mathrm{Ba}_{1-x} \mathrm{Na}_{x} \mathrm{Ti}_{2} \mathrm{Sb}_{2} \mathrm{O}$ with $\mathrm{T}_{c}$ systematically increasing with the $\mathrm{Na}$ content up to $\mathrm{x}=0.2$. The large shielding signal and a significant Meissner effect indicate the bulk nature of the superconducting phase. Similar susceptibility data for $\mathrm{Ba}_{1-x} \mathrm{Na}_{x} \mathrm{Ti}_{2} \mathrm{Sb}_{2} \mathrm{O}$ have been reported recently and confirm the results of Fig. $8 \mathrm{~b}$ with regard to the magnitude of magnetic shielding as well as the critical temperatures. 35

The increase of $T_{c}$ with the sodium content shows that the stability of the super- 

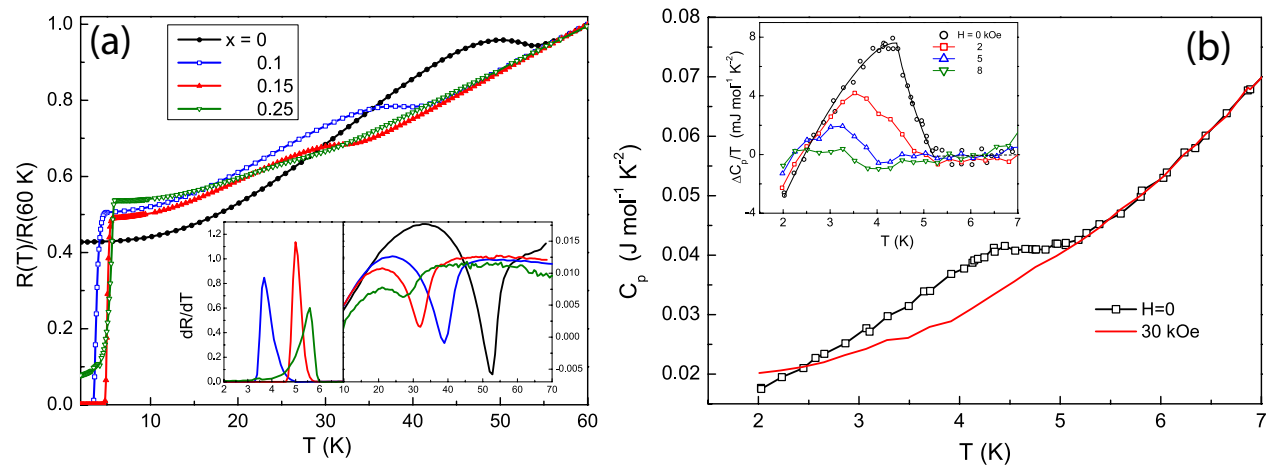

Fig. 9. (a) Resistance of $\mathrm{Ba}_{1-x} \mathrm{Na}_{x} \mathrm{Ti}_{2} \mathrm{Sb}_{2} \mathrm{O}$ for various $\mathrm{Na}$ concentrations $\mathrm{x}$. The inset shows the derivative used to define $\mathrm{T}_{c}$ (peak, left panel) and $\mathrm{T}_{D W}$ (dip, right panel). (b) Heat capacity of $\mathrm{Ba}_{0.85} \mathrm{Na}_{0.15} \mathrm{Ti}_{2} \mathrm{Sb}_{2} \mathrm{O}$.

conducting state is controlled by the charge carrier density, similar to copper and iron based high-temperature superconductors. More interestingly, the characteristic signature of the DW transition, a hump-like anomaly in the resistivity curves, is still observed for sodium contents up to $25 \%$, as shown in Fig. 9 a. The sizable peak of the heat capacity and it's characteristic dependence on magnetic fields, shown in Fig. 9b for $\mathrm{x}=0.15$, proves the bulk nature of superconductivity in the sodium doped compound. The superconducting phase coexists with the density wave phase at low temperatures. The critical temperature $\mathrm{T}_{D W}$, as determined from the dip in $d R / d T$ (right inset in Fig. 9a), seems to level off with increasing $\mathrm{x}$ at about 30 $\mathrm{K}$. This is in contrast to the spin density wave phase of the iron pnitide superconductors where the SDW transition is sharply suppressed upon charge doping and it extrapolates to zero at a critical doping, revealing a (hidden) quantum critical point. For Na concentrations above $25 \%$, the DW anomaly could not be resolved any more in resistivity measurements. The phase diagram of $\mathrm{Ba}_{1-x} \mathrm{Na}_{x} \mathrm{Ti}_{2} \mathrm{Sb}_{2} \mathrm{O}$ is shown in Fig. 10 for $x$ values up to the Na solubility limit.

Hole doping by alkali metal substitution for barium was also achieved using potassium and rubidium. The increase of $\mathrm{T}_{c}$ and the decrease of $\mathrm{T}_{D W}$, reported in $\mathrm{Ba}_{1-x} \mathrm{~K}_{x} \mathrm{Ti}_{2} \mathrm{Sb}_{2} \mathrm{O}, 27$ are shown in the phase diagram of Fig. 10 $\mathrm{b}$. The maximum of $\mathrm{T}_{c} \simeq 6.1 \mathrm{~K}$ was obtained at $\mathrm{x}_{K}=0.12$ in $\mathrm{Ba}_{1-x} \mathrm{~K}_{x} \mathrm{Ti}_{2} \mathrm{Sb}_{2} \mathrm{O}$ with a quickly decreasing superconducting shielding signal at higher doping concentrations. The decrease of $\mathrm{T}_{D W}$ with $\mathrm{x}_{K}$ with a concave curvature and an apparent saturation above $\mathrm{x}_{K}=0.1$ mimics the phase diagram of $\mathrm{Ba}_{1-x} \mathrm{Na}_{x} \mathrm{Ti}_{2} \mathrm{Sb}_{2} \mathrm{O}$.

Doping rubidium into the barium site increases $\mathrm{T}_{c}$ of $\mathrm{Ba}_{1-x} \mathrm{Rb}_{x} \mathrm{Ti}_{2} \mathrm{Sb}_{2} \mathrm{O}$ up to $5.4 \mathrm{~K}$ at optimal doping of $\mathrm{x}=0.2$, similar to $\mathrm{Ba}_{1-x} \mathrm{Na}_{x} \mathrm{Ti}_{2} \mathrm{Sb}_{2} \mathrm{O} .28$ The critical temperature of the DW phase, however, appeared to decrease faster and $\mathrm{T}_{D W}$ was extrapolated to zero at a critical doping of $\mathrm{x}=0.12$. This behavior seems to be different from other hole-doped $\mathrm{BaTi}_{2} \mathrm{Sb}_{2} \mathrm{O}$ compounds, however, one should 
take into account that the definition of $\mathrm{T}_{D W}$ from resistivity data for larger $\mathrm{x}$ values becomes less certain due to the disappearance of the characteristic humplike anomaly.

Whereas alkali metal ions like $\mathrm{Na}, \mathrm{K}, \mathrm{Rb}$ replace the $\mathrm{Ba}$ ions outside the $\mathrm{Sb}-\mathrm{Ti}_{2} \mathrm{O}$-Sb layer with a minimal structural impact on the active superconducting block, hole doping can also be achieved by substituting tin for antimony in

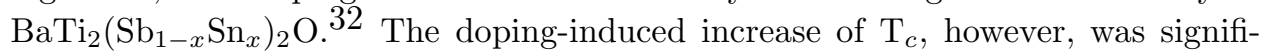
cantly smaller with a maximum of $2.5 \mathrm{~K}$ at $\mathrm{x}=0.3$. The phase diagram and the decrease of $\mathrm{T}_{D W}$ with the concave curvature is very similar to the cases where $\mathrm{Ba}$ was replaced by $\mathrm{Na}$ and $\mathrm{K}$. The smaller $\mathrm{T}_{c}$ in $\mathrm{BaTi}_{2}\left(\mathrm{Sb}_{1-x} \mathrm{Sn}_{x}\right)_{2} \mathrm{O}$ may be due to disorder effects introduced into the active $\mathrm{Sb}_{-} \mathrm{Ti}_{2} \mathrm{O}-\mathrm{Sb}$ block. The partially covalent bond between the Ti and $\mathrm{Sb}$ ions are perturbed by $\mathrm{Sn}$ substitution which gives rise to chemical disorder affecting the hybridization of titanium and pnictogen states at the Fermi energy. The covalent character of the Ti-Sb bond was also suggested to reduce the effective, tin doping-induced charge transfer to the $\mathrm{Ti}_{2} \mathrm{O}$ plane. 32

The existing gross similarities, but also the subtle differences, in the physical properties and the superconducting/density wave phase diagrams of hole-doped pnictide oxides raise the question whether or not changes of the structural parameters induced by the ionic substitutions are essential, besides the obvious doping of holes into the active layer. The effects of potassium, sodium, and rubidium doping on the lattice constants of $\mathrm{Ba}_{1-x} \mathrm{~A}_{x} \mathrm{Ti}_{2} \mathrm{Sb}_{2} \mathrm{O}(\mathrm{A}=\mathrm{Na}, \mathrm{K}, \mathrm{Rb})$ are qualitatively similar with $a$ decreasing and $c$ increasing with $\mathrm{x}$, however, the overall volume change is different. In $\mathrm{Ba}_{1-x} \mathrm{Na}_{x} \mathrm{Ti}_{2} \mathrm{Sb}_{2} \mathrm{O}$ the unit cell volume clearly decreases whereas $\mathrm{Ba}_{1-x} \mathrm{~K}_{x} \mathrm{Ti}_{2} \mathrm{Sb}_{2} \mathrm{O}$ shows a slight but continuous increase with $\mathrm{x} \cdot 27$ The volume of $\mathrm{Ba}_{1-x} \mathrm{Rb}_{x} \mathrm{Ti}_{2} \mathrm{Sb}_{2} \mathrm{O}$ also decreases, but the rate of decrease is much smaller than in the Na-doped compound $\frac{28}{28}$ The effect of tin doping is different, both lattice parameters $a$ and $c$ decrease with $\mathrm{x}$, resulting in a volume decrease comparable with that of $\mathrm{Ba}_{1-x} \mathrm{Na}_{x} \mathrm{Ti}_{2} \mathrm{Sb}_{2} \mathrm{O} \stackrel{32}{ }$

Despite the different responses of the unit cell parameters to doping, the stability of the superconducting and DW phases and the resulting phase diagrams are very similar, as shown in Fig. 10. This indicates that the charge transfer to or from the active layer is the most relevant parameter determining the properties of hole-doped $\mathrm{BaTi}_{2} \mathrm{Sb}_{2} \mathrm{O}$.

\subsection{Isovalent substitution of $S b$ by $A s$ and $B i$}

Isovalent doping of $\mathrm{BaTi}_{2} \mathrm{Sb}_{2} \mathrm{O}$ with $\mathrm{Bi}$ was reported to increase the superconducting critical temperature of $\mathrm{BaTi}_{2}\left(\mathrm{Sb}_{1-x} \mathrm{Bi}_{x}\right)_{2} \mathrm{O}$ up to $3.7 \mathrm{~K}$ at the optimal $\mathrm{x}=0.17$. At higher $\mathrm{x}$ values (up to $\mathrm{x}=0.4$ ), $\mathrm{T}_{c}$ decreased again and the temperature coefficient of the resistivity changed sign, indicating a metal-nonmetal transition near $\mathrm{x}=0.32 .29$ The DW phase was further suppressed with $\mathrm{T}_{D W}$ decreasing to about $40 \mathrm{~K}$ at $\mathrm{x}=0.13$ and the characteristic anomaly in resistivity and magnetization could not be discerned any more at $x=0.17$. The phase diagram derived from resistivity and 

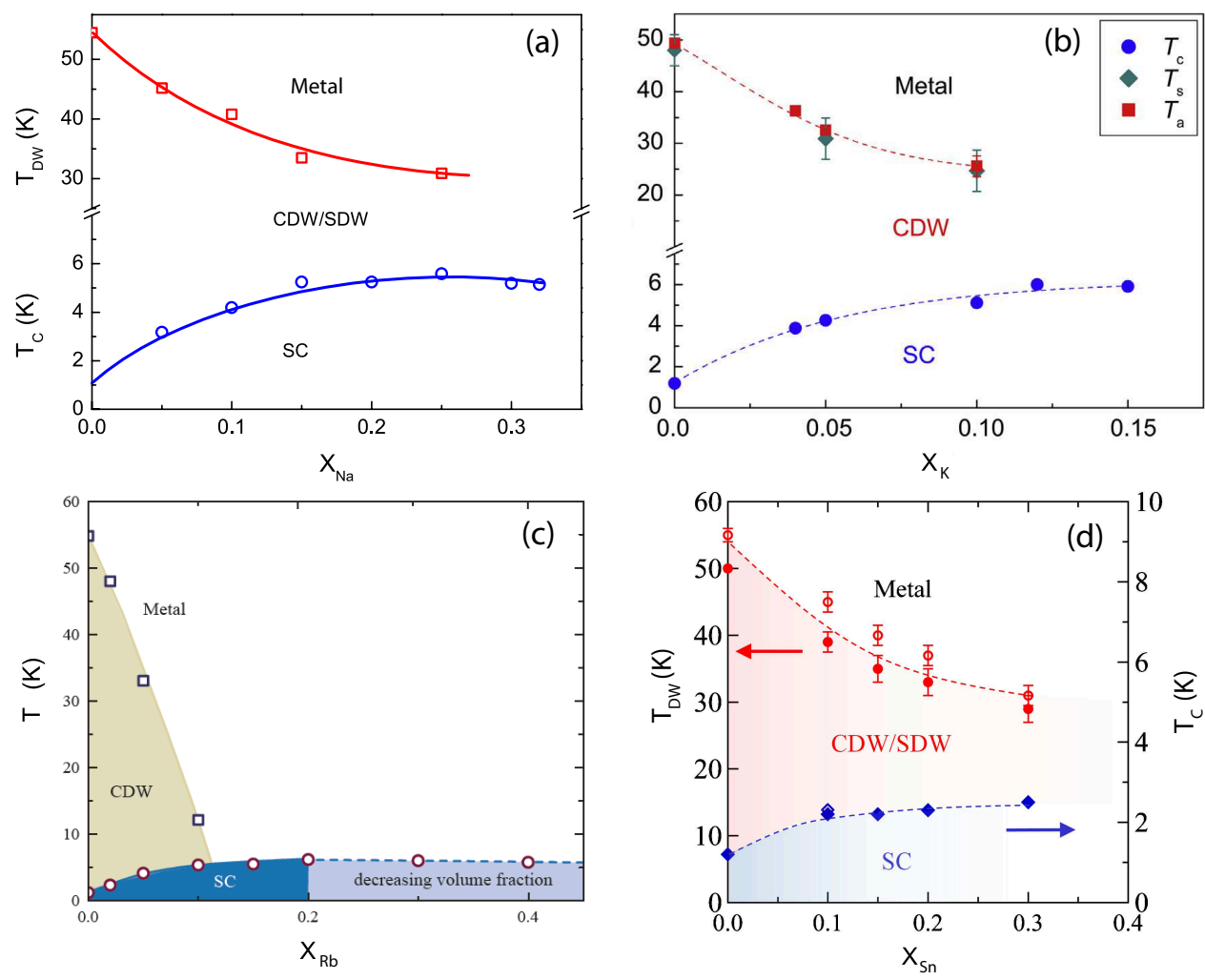

Fig. 10. Phase diagrams of hole-doped $\mathrm{BaTi}_{2} \mathrm{Sb}_{2} \mathrm{O}$. (a) $\mathrm{Ba}_{1-x} \mathrm{Na}_{x} \mathrm{Ti}_{2} \mathrm{Sb}_{2} \mathrm{O}$ (Ref. [20]), (b) $\mathrm{Ba}_{1-x} \mathrm{~K}_{x} \mathrm{Ti}_{2} \mathrm{Sb}_{2} \mathrm{O}$, (Reprinted with the publisher's permission from U. Pachmayr and D. Johrendt, Solid State Sciences 28, 31 (2014)), (c) $\mathrm{Ba}_{1-x} \mathrm{Rb}_{x} \mathrm{Ti}_{2} \mathrm{Sb}_{2} \mathrm{O}$, (Reprinted with the publisher's permission from F. von Rohr et al., Phys. Rev. B 89, 094505 (2014)), (d) $\mathrm{BaTi}_{2}\left(\mathrm{Sb}_{1-x} \mathrm{Sn}_{x}\right)_{2} \mathrm{O}$, (Reprinted with the publisher's permission from K. Nakano et al., J. Phys. Soc. Jpn. 82, 074707 (2013))

magnetization measurements is shown in Fig. 6b. The decrease of $\mathrm{T}_{D W}$ follows the trend with increasing ionic radius of the pnictogen, starting from $\mathrm{BaTi}_{2} \mathrm{As}_{2} \mathrm{O}$ $\left(\mathrm{T}_{D W}=200 \mathrm{~K}\right)$ to $\mathrm{BaTi}_{2} \mathrm{Sb}_{2} \mathrm{O}\left(\mathrm{T}_{D W}=54 \mathrm{~K}\right)$ and finally to $\mathrm{BaTi}_{2}\left(\mathrm{Sb}_{0.87} \mathrm{Bi}_{0.13}\right)_{2} \mathrm{O}$ $\left(\mathrm{T}_{D W}=40 \mathrm{~K}\right)$.

It is important to consider any possible impurity phase which might be superconducting in $\mathrm{Bi}$ containing compounds. It is known, for example, that $\mathrm{BaBi}_{3}$ is superconducting at $5.7 \mathrm{~K} \cdot 36$ Pure bismuth, not superconducting in the crystalline state, can become superconducting in its amorphous form, with $\mathrm{T}_{c}$ above $6 \mathrm{~K} ! 37 \mathrm{In}$ $\mathrm{BaTi}_{2}\left(\mathrm{Sb}_{1-x} \mathrm{Bi}_{x}\right)_{2} \mathrm{O}$, the onset of a resistance drop as well as a small diamagnetic signal at higher temperatures (near $6 \mathrm{~K}$ ) was indeed observed and attributed to $\mathrm{Bi}$ impurities, also resolved in X-ray spectra. 29

Yajima et al. have synthesized the complete series of solid solutions of $\mathrm{BaTi}_{2}\left(\mathrm{Sb}_{1-x} \mathrm{As}_{x}\right)_{2} \mathrm{O}$ and $\mathrm{BaTi}_{2}\left(\mathrm{Sb}_{1-x} \mathrm{Bi}_{x}\right)_{2} \mathrm{O}$ for $0 \leq \mathrm{x} \leq 1.31$ The smooth increase 
of both lattice parameters with $\mathrm{x}$, following Vegard's law over the whole concentration range, shows that the compounds form solid solutions. The complete phase diagram is shown in Fig. 6 $\mathrm{k}$. $\mathrm{T}_{D W}$ decreases smoothly from $200 \mathrm{~K}$ to $54 \mathrm{~K}$ in $\mathrm{BaTi}_{2}\left(\mathrm{Sb}_{1-x} \mathrm{As}_{x}\right)_{2} \mathrm{O}$, as expected. The superconducting $\mathrm{T}_{c}$, in $\mathrm{BaTi}_{2} \mathrm{Sb}_{2} \mathrm{O}$ at 1.2 $\mathrm{K}$, decreases to zero when a small amount of As is substituted for Sb. The domeshaped stability region of the superconducting phase for $\mathrm{Bi}$ doping up to $\mathrm{x}=0.4$ was also observed, similar to the report by Zhai et al ${ }^{[29}$ However, at higher Bi doping $(\mathrm{x} \geq 0.6)$, a reentrant superconducting phase was found 31 The $\mathrm{T}_{c}$ of this phase reaches a maximum of $4.6 \mathrm{~K}$ for $\mathrm{x}=1\left(\mathrm{BaTi}_{2} \mathrm{Bi}_{2} \mathrm{O}\right)$. Based on magnetic (zero field cooled) measurements, showing a relatively large shielding signal, the authors suggested that bulk superconductivity in this phase is intrinsic.

\subsection{Superconducting properties of pnictide oxides}

In view of the unconventional superconducting properties and pairing symmetries of the layered cuprates (d-wave pairing) and iron arsenides $\left(\mathrm{s}^{ \pm}\right.$pairing, two-gap superconductivity), the physical nature and the details of the superconducting state and the symmetry of the order parameter in pnictide oxides are of essential interest. Since in $\mathrm{BaTi}_{2} \mathrm{Sb}_{2} \mathrm{O}$ and it's hole doped variants superconductivity coexists with the density wave order, the possible competition or mutual interaction of both states may result in unconventional pairing mechanisms. Two possible scenarios have been discussed theoretically in recent first-principles calculations of $\mathrm{BaTi}_{2} \mathrm{Sb}_{2} \mathrm{O}$ and it's hole-doped analogue $38 \mid 39$ Interestingly, the possible symmetry of the superconducting gap depends on the nature of the density wave phase, spin (SDW) or charge density wave (CDW). A magnetic instability, caused by Fermi surface nesting, would result in the formation of a spin density wave and allow for spin-fluctuation mediated superconductivity and the possibility of a sign-changing

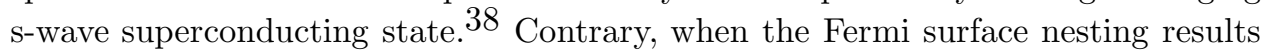
in a charge density wave, electron-phonon mediated superconductivity with the possibility of multiband character was suggested based on first-principle calculations of the phonon dispersions and the electron-phonon coupling. ${ }^{39}$ Details of the first-principles calculations will be discussed in Section 5 .

\subsubsection{Heat capacity}

The heat capacity of the superconducting state is a sensitive quantity, reflecting unconventional pairing symmetries or multigap superconductivity. Data available so far will be discussed in the following section. Because of the low superconducting transition temperatures $(1.2 \mathrm{~K}$ to $5.5 \mathrm{~K})$, meaningful heat capacity $\left(\mathrm{C}_{p}\right)$ measurements have to be extended to temperatures below $1 \mathrm{~K}$. A systematic study of the superconducting $\mathrm{C}_{p}$ to ${ }^{3} \mathrm{He}$ temperatures has been conducted for the hole-doped $\mathrm{Ba}_{1-x} \mathrm{Na}_{x} \mathrm{Ti}_{2} \mathrm{Sb}_{2} \mathrm{O} ! 40$ The results for $\mathrm{x}=0$ and $\mathrm{x}=0.15$ are shown in Fig. 11. The heat capacity of both compounds can be fit to a single-gap weak-coupling model. For $15 \% \mathrm{Na}$ doping, the data fit nearly perfectly to the BCS model, as shown by 

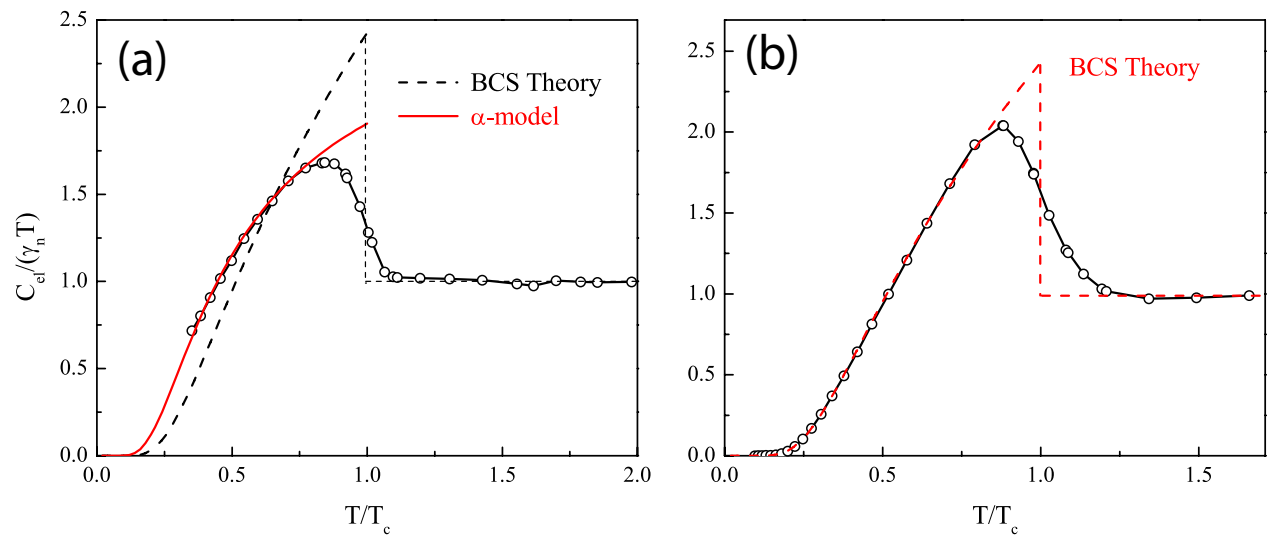

Fig. 11. Electronic heat capacity of (a) $\mathrm{BaTi}_{2} \mathrm{Sb}_{2} \mathrm{O}$ and (b) $\mathrm{Ba}_{0.85} \mathrm{Na}_{0.15} \mathrm{Ti}_{2} \mathrm{Sb}_{2} \mathrm{O}$. The dashed lines show the fit to the BCS theory. The $\mathrm{C}_{p}$ data of $\mathrm{BaTi}_{2} \mathrm{Sb}_{2} \mathrm{O}$ are better described by the single-gap $\alpha$ model, as discussed in the text.

the dashed line in Fig. 11 $\mathrm{b}$. The data for the undoped $\mathrm{BaTi}_{2} \mathrm{Sb}_{2} \mathrm{O}$, however, deviate significantly from the BCS function (Fig. 11 ). The best fit is provided by the $\alpha$-mode 41 which varies the zero-temperature superconducting gap value $\Delta(0)$ while maintaining the same relative temperature dependence $\Delta(T) / \Delta(0)$ according to the BCS model. The parameter $\alpha$ is defined as $\alpha=\Delta(0) / k_{B} T_{c}$ and the best fit for $\mathrm{BaTi}_{2} \mathrm{Sb}_{2} \mathrm{O}$ is obtained for $\alpha \approx 1.4$ (note that $\alpha=1.764$ in the BCS theory). The normal state Sommerfeld constant, $\gamma_{n}$, is obtained as $10.9 \mathrm{~mJ} /\left(\mathrm{mol} \mathrm{K}^{2}\right)$ and 13 $\mathrm{mJ} /\left(\mathrm{mol} \mathrm{K}^{2}\right)$ for $\mathrm{x}=0$ and $\mathrm{x}=0.15$, respectively, in good agreement with calculated values $\frac{38}{18}$

The heat capacity data of $\mathrm{BaTi}_{2} \mathrm{Sb}_{2} \mathrm{O}$, shown in Fig. 117, are consistent with data reported by Yajima et al $\frac{19}{19}$, however, in the latter case the large width of the superconducting transition made it difficult to fit $\mathrm{C}_{p}(\mathrm{~T})$ to a more detailed model (see Fig. 7b).

Results of heat capacity measurements of other hole-doped $\mathrm{BaTi}_{2} \mathrm{Sb}_{2} \mathrm{O}$ compounds are consistent with the above conclusions. In $\mathrm{Ba}_{0.8} \mathrm{Rb}_{0.2} \mathrm{Ti}_{2} \mathrm{Sb}_{2} \mathrm{O}$, the heat capacity jump at $\mathrm{T}_{c}=5.4 \mathrm{~K}, \Delta C_{p} / \gamma_{n} T_{c}=1.57$, is compatible with the BCS model and the normal state $\gamma_{n}=14 \mathrm{~mJ} /\left(\mathrm{mol} \mathrm{K}^{2}\right)$ is nearly the same as the value for $\mathrm{Ba}_{0.85} \mathrm{Na}_{0.15} \mathrm{Ti}_{2} \mathrm{Sb}_{2} \mathrm{O}$ discussed above.28 $\mathrm{A}$ more detailed fit to the BCS or $\alpha$ models seems not feasible since the data are limited to $\mathrm{T}>2 \mathrm{~K}$. Heat capacity data of $\mathrm{BaTi}_{2}\left(\mathrm{Sb}_{0.9} \mathrm{Sn}_{0.1}\right)_{2} \mathrm{O}$ have also been found to be consistent with a single-gap BCS model with $\Delta C_{p} / \gamma_{n} T_{c}=1.39$ at $\mathrm{T}_{c}=2.3 \mathrm{~K}$ and $\gamma_{n}=17.1 \mathrm{~mJ} /\left(\mathrm{mol} \mathrm{K}^{2}\right) ! 32$

All heat capacity data published so far are consistent with a weak-coupling single-gap BCS description, although the unconventional, spin-fluctuation mediated pairing mechanism 38 cannot be completely ruled out. Furthermore, the data do not show any signature of multiple superconducting gaps, as suggested by Subedi. $\frac{39}{}$ Further evidence for conventional weak-coupling superconductivity in 

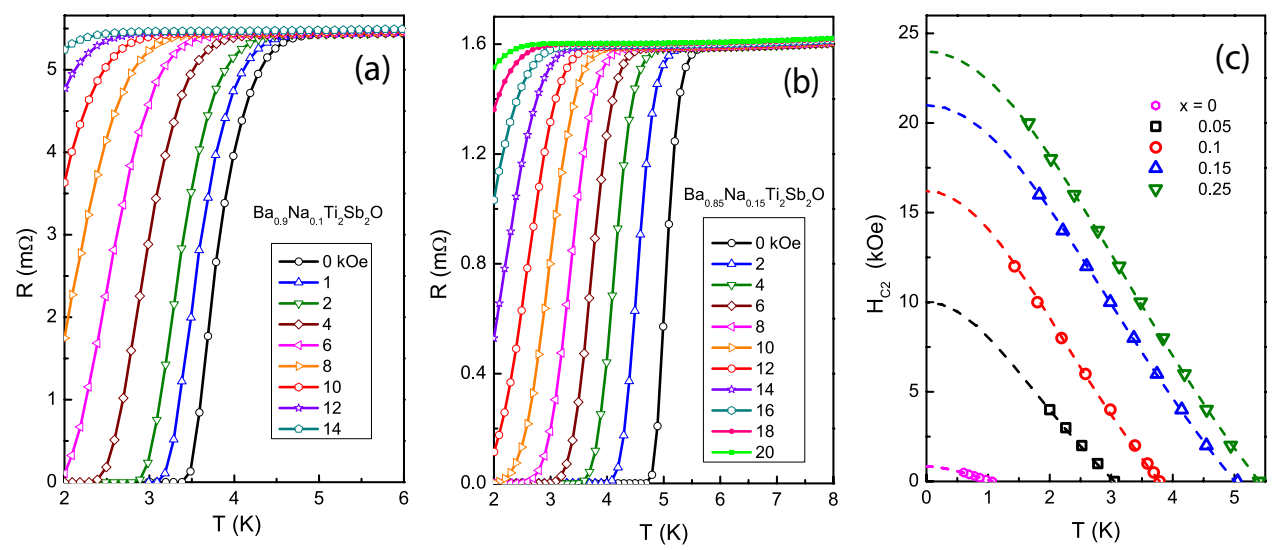

Fig. 12. Resistivity of $\mathrm{Ba}_{1-x} \mathrm{Na}_{x} \mathrm{Ti}_{2} \mathrm{Sb}_{2} \mathrm{O}$ in magnetic fields. (a) $\mathrm{x}=0.1$ (b) $\mathrm{x}=0.15$ (c) Upper critical fields $\mathrm{H}_{c 2}$ as derived from resistivity data.

pnictide oxides was derived from muon spin rotation measurements (London penetration depth) of $\mathrm{Ba}_{1-x} \mathrm{Na}_{x} \mathrm{Ti}_{2} \mathrm{Sb}_{2} \mathrm{O}=35$ and $\mathrm{BaTi}_{2}\left(\mathrm{As}_{1-x} \mathrm{Sb}_{x}\right)_{2} \mathrm{O}, \stackrel{30}{\text { with no clear }}$ indication of multiple superconducting gaps. Support for an ordinary s-wave superconducting state in $\mathrm{BaTi}_{2} \mathrm{Sb}_{2} \mathrm{O}$ was also derived from ${ }^{121 / 123} \mathrm{Sb}$ nuclear magnetic and quadrupole resonance experiments revealing the existence of a coherence peak at $\mathrm{T}_{c}$ in the $1 / \mathrm{T}_{1}$ vs. temperature data. $\frac{42}{42}$

\subsubsection{Upper and lower critical fields}

The upper critical field, $\mathrm{H}_{c 2}$, can be determined from field-dependent resistivity measurements. An example is shown in Fig. 12 for the system $\mathrm{Ba}_{1-x} \mathrm{Na}_{x} \mathrm{Ti}_{2} \mathrm{Sb}_{2} \mathrm{O}$. The extrapolation to zero temperature (dashed lines in Fig. 12k) yields $\mathrm{H}_{c 2}$ values between $0.8 \mathrm{kOe}(\mathrm{x}=0)$ and $24 \mathrm{kOe}(\mathrm{x}=0.25)$. These numbers can be used to estimate the (average) coherence length $\xi(0)$ which decreases from $640 \AA$ for $\mathrm{x}=0$ to $120 \AA$ for $\mathrm{x}=0.25$. These data are in excellent agreement with other hole-doped $\mathrm{BaTi}_{2} \mathrm{Sb}_{2} \mathrm{O}$ compounds. 28

The lower critical field $\mathrm{H}_{c 1}$, which is related to the London penetration depth $\lambda$, was measured for the optimally doped $\mathrm{Ba}_{1-x} \mathrm{Rb}_{x} \mathrm{Ti}_{2} \mathrm{Sb}_{2} \mathrm{O}{ }^{28}$ With the value of $\mathrm{H}_{c 1} \approx 38$ Oe and the upper critical field $\mathrm{H}_{c 2}=23 \mathrm{kOe}$, the Ginzburg-Landau parameter can be estimated as $\kappa \approx 35$, revealing that pnictide oxides are strongly type-II superconductors. Accordingly, the magnetic penetration depth for this compound is $\lambda=\kappa \xi \approx 4200 \AA 28$

\subsubsection{Pressure effects on superconductivity}

The effect of hydrostatic pressure on the superconducting state was studied extensively for conventional as well as unconventional superconductors. ${ }^{43} 14$ The control of fundamental parameters, like the phonon energy, electron-phonon coupling 

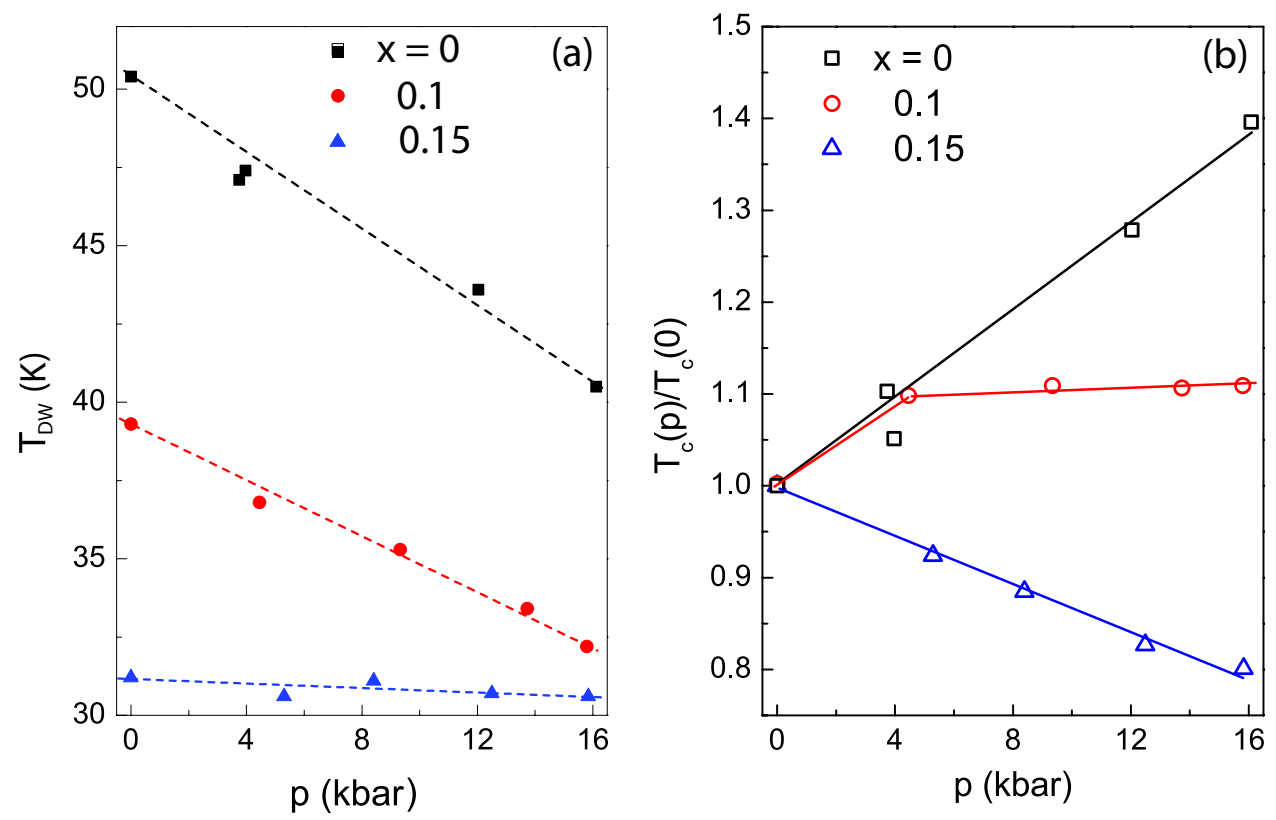

Fig. 13. Pressure effect on superconducting and density wave phases of $\mathrm{Ba}_{1-x} \mathrm{Na}_{x} \mathrm{Ti}_{2} \mathrm{Sb}_{2} \mathrm{O}$. (a) $\mathrm{T}_{D W}$ vs. pressure. (b) $\mathrm{T}_{c}$ vs. pressure. The error bars in (b) show the width of the resistive transition between $90 \%$ and $10 \%$ of the resistance drop.

strength, charge transfer and chemical bonds, etc. by external pressure result in complex responses of the superconducting state to the lattice compression. On the other hand, a systematic study of the stability of the superconducting state with respect to pressure can also illuminate the microscopic mechanisms and fundamental interactions leading to superconductivity.

In superconducting pnictide oxides, the effects of pressure on the superconducting $\mathrm{T}_{c}$ and the density wave order $\left(\mathrm{T}_{D W}\right)$ are of specific interest and have been investigated very recently. ${ }^{44}$ The hole-doped $\mathrm{Ba}_{1-x} \mathrm{Na}_{x} \mathrm{Ti}_{2} \mathrm{Sb}_{2} \mathrm{O}$ was studied at three typical doping states, for $\mathrm{x}=0$ (undoped), $\mathrm{x}=0.1$ (underdoped), and $\mathrm{x}=0.15$ (optimally doped). The density wave phase was suppressed for all doping levels, however, the rate of decrease of $\mathrm{T}_{D W}$ showed a strong dependence on the Na content $\mathrm{x}$, with the largest rate at $\mathrm{x}=0$ and only a very minute decrease of $\mathrm{T}_{D W}$ at $\mathrm{x}=0.15$. The pressure effect on the density wave transition temperature is summarized in Fig. 13 a.

The relative change of the superconducting $\mathrm{T}_{c}$ with pressure is shown in Fig. 13 b. Similar to most cuprate and iron arsenide superconductors, the pressure coefficient of $\mathrm{T}_{c}$ strongly depends on the doping state. The critical temperature of the undoped compound $\left(\mathrm{BaTi}_{2} \mathrm{Sb}_{2} \mathrm{O}\right)$ increases by $40 \%$ with compression to $16 \mathrm{kbar}$. At $10 \%$ sodium doping, $\mathrm{T}_{c}$ initially increases at low $\mathrm{p}$ but then saturates with further increasing pressure. The overall $\mathrm{T}_{c}$ increase does not exceed about $10 \%$. For the op- 
timally doped sample, however, the opposite trend is observed, the superconducting $\mathrm{T}_{c}$ decreases linearly with increasing pressure.

It should be noted that a similar doping dependence of the pressure coefficient of $\mathrm{T}_{c}$ was reported in high-pressure studies of cuprate high-temperature superconductors 43 as well as iron arsenide superconductors. ${ }^{45 \mid 46}$ In cuprate superconductors, the pressure effects have been understood as a charge transfer to the active superconducting layer induced by pressure and the general dome-shaped $\mathrm{T}_{c}$ vs. doping phase diagram. In iron arsenide superconductors, the proximity of the superconducting state to a spin density wave phase, the possible competition between both phases, and the pressure effect on this phase was considered as an additional circumstance that had to be taken into account.

In $\mathrm{Ba}_{1-x} \mathrm{Na}_{x} \mathrm{Ti}_{2} \mathrm{Sb}_{2} \mathrm{O}$ the active superconducting layer is the $\mathrm{Sb}-\mathrm{TiO}_{2}-\mathrm{Sb}$ slab with charge doping provided by the $\mathrm{Na}$ ions occupying $\mathrm{Ba}$ sites in between the active layers. A charge transfer induced by pressure to the active layer seems unlikely, but not impossible. However, since the Sb $5 p$ states mix with the Ti $3 d$ states at the Fermi surface (Sb-Ti bonds), an effect of pressure on the Fermi surface resulting in a redistribution of charges as well as a change of the nesting property cannot be ruled out. In addition, the suppression of the density wave state by pressure, which is particularly pronounced at low doping levels, can contribute to the rise of $\mathrm{T}_{c}$ of the undoped or underdoped compounds. The critical temperature of the density wave state is almost not affected by pressure for optimal doping (Fig. 13a) and other effects such as a reduction of the density of states at the Fermi level due to pressure-induced band broadening etc. can dominate and result in the observed $\mathrm{T}_{c}$ decrease for $\mathrm{x}=0.15$.

The apparent anticorrelation between the pressure changes of $\mathrm{T}_{D W}$ and $\mathrm{T}_{c}$ lead to the conjecture that both ordered phases actually compete with one another, leading to a $\mathrm{T}_{c}$ enhancement whenever the density wave phase is suppressed by pressure (as in the undoped $\mathrm{BaTi}_{2} \mathrm{Sb}_{2} \mathrm{O}$ ). This tendency is similar to the effect of doping on both states, with increasing hole doping $\mathrm{T}_{D W}$ decreases and $\mathrm{T}_{c}$ increases. A more fundamental and complete understanding of the effects of external pressure on both states, however, needs additional work, also involving superconducting pnictide oxides with isovalent substitutions.

\subsection{The density wave state: Spin or charge density?}

The nature of the density wave phase is crucial for the understanding of superconductivity in pnictide oxides and how both states coexist and accommodate each other. The strong nesting of the Fermi surface, first discussed by Pickett based on first-principles calculations of $\mathrm{Na}_{2} \mathrm{Ti}_{2} \mathrm{Sb}_{2} \mathrm{O}, \frac{34}{4}$ can explain the observed instability (near $\mathrm{T}_{D W}=114 \mathrm{~K}$ in $\mathrm{Na}_{2} \mathrm{Ti}_{2} \mathrm{Sb}_{2} \mathrm{O}$ ) as the formation of a spin or charge density wave with corresponding anomalies of the magnetic susceptibility and the resistivity (see Fig. 3). The question of whether the phase below $\mathrm{T}_{D W}$ is defined by a spin or a charge density wave has been a matter of discussion since then. 
Early studies revealing the sharp drop of the magnetic susceptibility (see Figs. [3 $\mathrm{b}$, 4 $\mathrm{b}$, and $5 \mathrm{~b}$ ) suggested the opening of a spin gap, possibly due to a spin-Peierls transition. 21 The high-temperature property of the susceptibility implies that the main magnetic exchange interactions are $\mathrm{Ti}-\mathrm{Sb}-\mathrm{Ti}$ superexchange, but not Ti-O$\mathrm{Ti}$ interactions. Theoretical calculations confirm the hybridization of $\mathrm{Ti} d$ states with $\mathrm{Sb} p$ states but also emphasize on the importance of direct Ti $d$ - $d$ overlap. $\underline{34}$ Neutron scattering experiments, however, have not detected a sizable magnetic moment that could be associated with static magnetic order $22|30| 47 \mid 48$ The absence of static magnetic order is further suggested by muon spin relaxation studies of $\mathrm{BaTi}_{2}\left(\mathrm{As}_{1-x} \mathrm{Sb}_{x}\right)_{2} \mathrm{O}$ and $\mathrm{Ba}_{1-x} \mathrm{Na}_{x} \mathrm{Ti}_{2} \mathrm{Sb}_{2} \mathrm{O} \underline{30} 35$

It should be noted that the absence of a sizable static magnetically ordered moment does not exclude the possibility of the formation of a spin density wave state if the ordered magnetic moment is very small, below the resolution of the neutron or muon spin relaxation experiments. However, the missing proof of a detectable magnetic moment below $\mathrm{T}_{D W}$ is in favor of the formation of a charge density wave, with strong coupling of the carriers to the lattice. Anomalies of both lattice constants near $\mathrm{T}_{D W}$ have in fact been observed in neutron scattering studies of $\mathrm{Na}_{2} \mathrm{Ti}_{2} \mathrm{Sb}_{2} \mathrm{O}$ although no lattice dimerization or superstructures have been reported 47 The structural distortion mainly increases the Ti-Ti distance and reduces the direct overlap with a partial opening of a band gap. The Ti $d^{1}$ electrons become slightly more localized which explains the increase of the resistivity just below $\mathrm{T}_{D W}$. Recent optical spectroscopy experiments show the opening of a density wave-like energy gap at $\mathrm{T}_{D W}$ removing most of the free carrier spectral weight with a simultaneous reduction of the scattering rate $\underline{49}$

\section{First-principles calculations of the electronic structure}

The nature of the density wave order in pnictide oxides (with $P n=\mathrm{As}, \mathrm{Sb}$ ) is one key to understand the superconductivity in these compounds. First theoretical work by Pickett did reveal the nesting property in form of a zone corner (M-point) boxlike Fermi surface ${ }^{34}$ The local spin-density approximation, applied to $\mathrm{Na}_{2} \mathrm{Ti}_{2} \mathrm{Sb}_{2} \mathrm{O}$, confirmed the nearly ionic picture with $\mathrm{Na}^{1+}, \mathrm{Ti}^{3+}, \mathrm{Sb}^{3-}$, and $\mathrm{O}^{2-}$. The valence electrons of $\mathrm{Ti}^{3+}$ are in $3 d^{1}$ state, i.e there is one $3 d$ electron per Ti ion with total spin $1 / 2$. Note the apparent analogy to the $3 d^{9}$ state of $\mathrm{Cu}^{2+}$ in the copper oxide superconductors with one spin- $1 / 2$ hole per $\mathrm{Cu}$ at the Fermi level. The direct $d$ - $d$ orbital overlap and the hybridization with $p$ states from antimony and oxygen result in the delocalization of the Ti $d$ states and the metallic properties of $\mathrm{Na}_{2} \mathrm{Ti}_{2} \mathrm{Sb}_{2} \mathrm{O}$. Accordingly, the density of states at the Fermi energy is mostly composed of Ti $d$ states with some contribution from the $\mathrm{Sb}$ and $\mathrm{O} p$ orbitals.

The simulation of different kinds of ferromagnetic or antiferromagnetic long range order by Pickett $\frac{34}{3}$ have not revealed a stable magnetic ground state with ordering of the magnetic Ti $3 d^{1}$ moments. Therefore, the formation of a spin- or charge-density wave which originates from the nesting property of the box-like sec- 

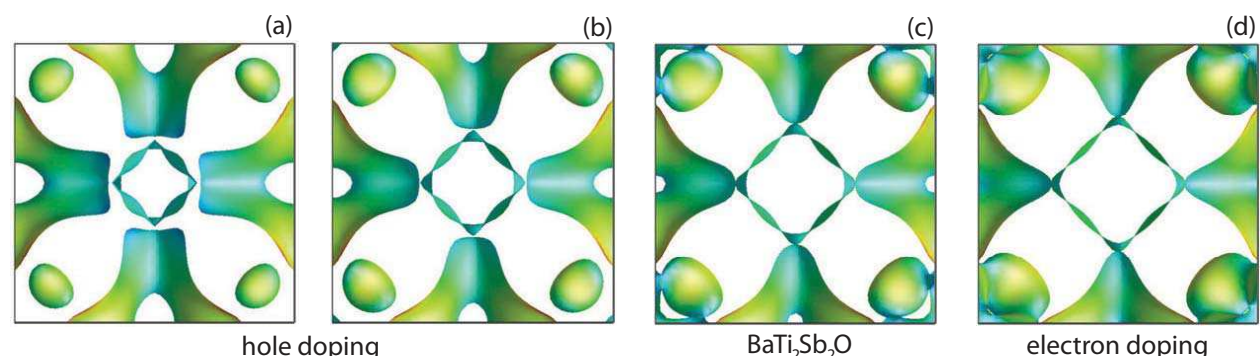

Fig. 14. Fermi surface of doped $\mathrm{BaTi}_{2} \mathrm{Sb}_{2} \mathrm{O}$ viewed along the $c$-axis. (a) and (b): $E_{F}<0$, hole doping (Ba substituted by $\mathrm{Na}, \mathrm{K}, \mathrm{Rb}$ ), (c): $E_{F}=0, \mathrm{BaTi}_{2} \mathrm{Sb}_{2} \mathrm{O},(\mathrm{d}): E_{F}>0$, electron doping. Reprinted with the publisher's permission from D. J. Singh, NJP 14, 123003 (2012).

tion of the Fermi surface with mostly Ti $d$ character was suggested.

The existence of nested sections of the Fermi surface in $\mathrm{NaTi}_{2} \mathrm{Sb}_{2} \mathrm{O}$ around the $\mathrm{M}$ point with a pseudo one-dimensional character was confirmed by a tight-binding band structure calculation (extended Hückel method) $\stackrel{[50}{=}$ It was suggested that a charge density wave with an incommensurate modulation and an associated lattice distortion would lead to the anomaly of the resistivity observed at $\mathrm{T}_{D W}=120 \mathrm{~K}$ for this compound (Fig. 3b). The structural distortion affecting the $a$ and $c$ axis lattice parameters and the $a / c$ ratio was indeed observed in powder neutron scattering experiments,$\stackrel{47}{ }$ but no superlattice reflections of magnetic or lattice origin could be resolved.

For a better understanding of the electronic structure, the character of the occupied Ti $d$ bands is essential. The nested box Fermi surface is comprised of almost exclusively $\mathrm{Ti} d_{x y}$ states with a significant overlap between the orbitals of neighbor-

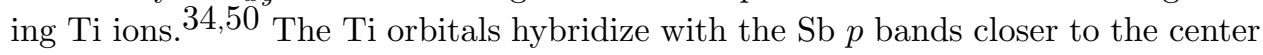
of the Brillouin zone. It should be noted that this is different from the $\mathrm{Cu} 3 d$ orbitals in the copper oxide superconductors which have prominently $d_{x^{2}-y^{2}}$ character and mix with the oxygen $p$ bands.

The problem of possible magnetic order and its consequences for superconductivity in $\mathrm{Ba}_{1-x} \mathrm{Na}_{x} \mathrm{Ti}_{2} \mathrm{Sb}_{2} \mathrm{O}$ was discussed by Singh based on first-principles density functional calculations! 38 Similar to $\mathrm{Na}_{2} \mathrm{Ti}_{2} \mathrm{Sb}_{2} \mathrm{O}$, discussed in the previous paragraphs, the nearly ionic picture $\left(\mathrm{Ba}^{2+}, \mathrm{Ti}^{3+}, \mathrm{Sb}^{3-}, \mathrm{O}^{2-}\right)$ holds very well with $\mathrm{Ti}$ $d$ states hybridized with $\mathrm{Sb} p$ states providing most of the density of states near the Fermy energy. The Ti $d$ orbitals at the Fermi surface are a mixture of $d_{z^{2}}$, $d_{x^{2}-y^{2}}$, and $d_{x y}$, with a strong $d_{x y}$ character. The Fermi surface obtained is rather complex with electron- as well as hole-like sheets present. Most importantly, there exists a $2 \mathrm{D}$ square section stretching along the zone edge line (M-A) giving rise to the nesting property. Another nested region of the Fermi surface extends around the $\mathrm{X}$ point. The nesting wave vector along the orientation of the Ti square lattice is $(0.24,0.24,0)(2 \pi / \mathrm{a})$, in good agreement with earlier calculations. 50 The calculated Fermi surface is shown in Fig. 14 for different positions of the Fermi energy 
(corresponding to different doping levels). The nesting property of the box-shaped section around M-A is remarkably stable with respect to a variation of the Fermi energy $E_{F}$. Decreasing $E_{F}\left(E_{F}\right.$ is set to zero for $\left.\mathrm{BaTi}_{2} \mathrm{Sb}_{2} \mathrm{O}\right)$ below zero, corresponding to hole doping with $\mathrm{Na}, \mathrm{K}$, or $\mathrm{Rb}$, decreases the size but the square shape is approximately preserved. This may explain the extraordinary stability of the density wave phase upon hole doping (see Fig. 10), as first observed experimentally in $\mathrm{Ba}_{1-x} \mathrm{Na}_{x} \mathrm{Ti}_{2} \mathrm{Sb}_{2} \mathrm{O}$

A magnetic instability was found (due to the Fermi surface nesting) resulting in an ordered ground state with a double stripe spin structure which also lowers the symmetry from tetragonal to orthorhombic ${ }^{38}$ The ordered magnetic moment, however, is small $\left(\simeq 0.2 \mu_{B}\right)$, according to the calculations. Nevertheless, the coupling of the spin to the charge carriers appears to be significant with possible consequences for the superconducting state. The possibility of spin-fluctuation mediated superconductivity was consequently discussed and the pairing symmetry, consistent with the structure of the Fermi surface, was suggested to be a sign changing $s$-wave superconducting state. For this "unconventional" superconductivity it is important that the spin fluctuation dominate and the transition at $\mathrm{T}_{D W}$ results in the formation of a spin density wave.

More recent first-principles calculations of $\mathrm{Na}_{2} \mathrm{Ti}_{2} \mathrm{Pn}_{2} \mathrm{O}(\mathrm{Pn}=\mathrm{As}, \mathrm{Sb})$ have also concluded that the ground state is magnetically ordered 51$]$ The calculated band structures and Fermi surfaces are consistent with earlier calculations. ${ }^{34}$ The magnetic structure of the ground state depends on the pnictogen atom. For $P n=A s$, a checkerboard spin configuration was found to be stable, with four spins on a plaquette of neighboring Ti ions aligned with one another, forming a block spin with an antiferromagnetic order between different blocks. For $P n=\mathrm{Sb}$ the magnetic order is the double stripe structure described by Singh for $\mathrm{BaTi}_{2} \mathrm{Sb}_{2} \mathrm{O}$. The Fermi surface nesting as the origin of the magnetic orders is confirmed. A slightly different picture of the magnetic ground state was derived from electronic structure calculations of $\mathrm{BaTi}_{2} \mathrm{As}_{2} \mathrm{O} ! 52$ Only two of four Ti spins were found to order with antiparallel moments, driven by the Fermi surface nesting and the Coulomb interactions. No modulation of the charge density was found, favoring the formation of a spin density wave at the ordering temperature $\mathrm{T}_{D W}$.

It appears interesting that first-principles calculations of various pnictide-oxides reveal different ground states with double stripe, block spin, or partial magnetic orders. These magnetic structures are very close in energy, but they are all commensurate with the lattice. The nesting wave vector, however, is most likely incommensurate with the atomic structure and the true magnetic order may well be an incommensurate spin density wave. With the small ordered moment per Ti ion, it could be a challenge to detect the possible order in neutron scattering or other experiments.

First-principles calculations including the phonon dispersion spectrum and the electron-phonon interactions of $\mathrm{BaTi}_{2} \mathrm{Sb}_{2} \mathrm{O}$ have been presented by Subedi $\frac{39}{\text { It }}$ 
was concluded that, despite the tendency to a magnetic instability, the phonon dispersions may give rise to a lattice instability near the corners of the Brillouin zone which stabilizes a charge density wave phase. The electron-phonon coupling is strong enough to explain the superconducting phase in this compound as conventional phonon-mediated s-wave superconductivity. The calculated electron-phonon coupling constant, $\lambda_{e p}=0.55$, is in good agreement with the experimentally derived value 40

An analysis of the electronic structure and chemical bonding of $\mathrm{Na}_{2} \mathrm{Ti}_{2} \mathrm{Pn}_{2} \mathrm{O}$ and $\mathrm{BaTi}_{2} P n_{2} \mathrm{O}(P n=\mathrm{As}, \mathrm{Sb})$ has in part confirmed the results from earlier work $! 53$ The bonding between the $\mathrm{Ti}_{2} \mathrm{Pn}_{2} \mathrm{O}$ and $\mathrm{Na}_{2}(\mathrm{Ba})$ layers is mainly of ionic character, whereas the bonding within the $\mathrm{Ti}_{2} P n_{2} \mathrm{O}$ has also covalent character. $\mathrm{Ti} d_{x y}, d_{x^{2}-y^{2}}$, and $d_{z^{2}}$ states dominate the Fermi surface. Interestingly, the charge transfer to the $\mathrm{Ti}_{2} \mathrm{Pn}_{2} \mathrm{O}$ layer is smaller than expected from the nominal charges $\mathrm{Na}^{1+}$ and $\mathrm{Ba}^{2+}$. It decreases from 1.6 electrons per $\mathrm{Na}_{2}$ in $\mathrm{Na}_{2} \mathrm{Ti}_{2} \mathrm{As}_{2} \mathrm{O}$ to 1.23 electrons per $\mathrm{Ba}$ in $\mathrm{BaTi}_{2} \mathrm{Sb}_{2} \mathrm{O} .53$ This trend in the charge transfer from the cation to the $\mathrm{Ti}_{2} \mathrm{Pn}_{2} \mathrm{O}$ layer could be one relevant parameter which controls the superconducting state in pnictide oxides. It is interesting that superconductivity occurs among the four compounds only in $\mathrm{BaTi}_{2} \mathrm{Sb}_{2} \mathrm{O}\left(\mathrm{T}_{c}=1.2 \mathrm{~K}\right)$ with the smallest electron transfer and $\mathrm{T}_{c}$ was enhanced by $\mathrm{Na}$ (hole) doping, i.e. by a further reduction of the electron number in the active layer. Similar calculations for $\mathrm{BaTi}_{2} \mathrm{Bi}_{2} \mathrm{O}$, a pnictide oxide with no density wave phase but a relatively high superconducting $\mathrm{T}_{c}=4.6 \mathrm{~K}$, show an even smaller charge transfer of 1.18 electrons per Ba ion,, 54 which is consistent with the general trend mentioned above.

The role of the charge density in the active $\mathrm{Ti}_{2} \mathrm{Pn}_{2} \mathrm{O}$ layer is not completely understood and needs further studies. Within the rigid band model, the decrease of the electron number will change the density of states (DOS) at the Fermi energy, which is expected to increase since the Fermi energy is just on the high-energy slope of a peak of the DOS. On the other hand, the superconducting state appears to compete with the density wave state and reducing $\mathrm{T}_{D W}$ or suppressing the DW state completely leads to a superconducting phase, observed in $\mathrm{BaTi}_{2} \mathrm{Sb}_{2} \mathrm{O}$, its holedoped analogues, and $\mathrm{BaTi}_{2} \mathrm{Bi}_{2} \mathrm{O}$. Further experimental and theoretical studies are needed to deepen the understanding of the coexistence and mutual interactions of the density wave and superconducting states in the new Ti-based pnictide oxide superconductors.

\section{Summary}

Superconductivity in a novel transition metal pnictide oxide has attracted attention recently. This class of compounds with the chemical compositions $\mathrm{Na}_{2} \mathrm{Ti}_{2} \mathrm{Pn}_{2} \mathrm{O}$ and $\mathrm{BaTi}_{2} P n_{2} \mathrm{O}(P n=\mathrm{As}, \mathrm{Sb}, \mathrm{Bi})$ form layered structures with characteristic $\mathrm{Ti}_{2} P n_{2} \mathrm{O}$ slabs separated by either a double layer of $\mathrm{Na}_{2}$ or a single layer of Ba. Here the transition metal is $\mathrm{Ti}$ with one $3 d$ electron in the formal ionic $\mathrm{Ti}^{3+}$ state. Structurally, the $\mathrm{Ti}_{2} \mathrm{O}$ form a $2 \mathrm{D}$ lattice which is the anti-structure to the $\mathrm{CuO}_{2}$ planes 
of the copper oxide high temperature superconductors, i.e. the titanium and oxygen ions occupy the oxygen and copper sites in the $\mathrm{CuO}_{2}$ structure, respectively. The pnictogen ions are located above and below the $\mathrm{Ti}_{2} \mathrm{O}$ plane.

With the exception of $\mathrm{BaTi}_{2} \mathrm{Bi}_{2} \mathrm{O}$, all other compounds exhibit an instability at higher temperature which is most probably caused by a nesting feature of sections of the Fermi surface. The nature of this instability is not completely resolved yet, but there is evidence for the formation of a density wave state, through a modulation of either charge or spin density. The electronic states at the Fermi energy are dominated by Ti $d$ states partially hybridized with $p$ states of $P n$ and $\mathrm{O}$.

Superconductivity was discovered in $\mathrm{BaTi}_{2} \mathrm{Sb}_{2} \mathrm{O}$ at $1.2 \mathrm{~K}$ and $\mathrm{T}_{c}$ did increase through $\mathrm{Na}$ doping to a maximum of $5.5 \mathrm{~K}$. Interestingly, the density wave state was only slightly suppressed by $\mathrm{Na}$ (hole) doping and it coexists with the superconducting state in $\mathrm{Ba}_{1-x} \mathrm{Na}_{x} \mathrm{Ti}_{2} \mathrm{Sb}_{2} \mathrm{O}$ up to $\mathrm{x}=0.35$, the solubility limit of $\mathrm{Na}$ in the structure of $\mathrm{BaTi}_{2} \mathrm{Sb}_{2} \mathrm{O}$. Similar results have been obtained for other hole-doped samples using $\mathrm{K}$ and $\mathrm{Rb}$ replacing $\mathrm{Ba}$, or $\mathrm{Sn}$ replacing $\mathrm{Sb}$. The nature of the superconducting pairing has been a matter of discussion. It may be closely related to the nature of the density wave phase, spin or charge density. Various experimental techniques, designed to reveal information about the symmetry of the superconducting order parameter, have provided evidence in favor of a conventional BCS-like $s$-wave superconductivity. Furthermore, no signature of a magnetically ordered state could be detected although first-principles calculations did find stable magnetic ground states in different pnictide oxide compounds.

Superconductivity and the density wave order most likely compete with one another. Evidence for this competition is derived from the fact that a superconducting state is only observed when the critical temperature of the density wave transition is lowered to $54 \mathrm{~K}$ (in $\mathrm{BaTi}_{2} \mathrm{Sb}_{2} \mathrm{O}$ ) or completely suppressed (in $\mathrm{BaTi}_{2} \mathrm{Bi}_{2} \mathrm{O}$ ). Furthermore, doping and pressure dependent measurements show an anticorrelation between $\mathrm{T}_{c}$ and $\mathrm{T}_{D W}, \mathrm{~T}_{c}$ is enhanced when $\mathrm{T}_{D W}$ decreases.

On a microscopic level, there are several parameters that may affect the two ordered phases. With the increase of the $P n$ ionic size, the $a$ - and $c$-axis lattice parameters increase in both, $\mathrm{Na}_{2} \mathrm{Ti}_{2} \mathrm{Pn}_{2} \mathrm{O}$ and in $\mathrm{BaTi}_{2} \mathrm{Pn}_{2} \mathrm{O}$. Comparing $\mathrm{Na}_{2} \mathrm{Ti}_{2} \mathrm{Pn}_{2} \mathrm{O}$ and $\mathrm{BaTi}_{2} P n_{2} \mathrm{O}, a$ and $c$ are slightly smaller in the Ba compounds. An increase of $a$ will reduce the direct overlap of the Ti $d$ orbitals and also affect the hybridization with the $P n p$ states. Furthermore, the calculated charge transfer from the $\left(\mathrm{Na}^{1+}\right)_{2}$ and the $\mathrm{Ba}^{2+}$ layers is not complete and changes with the cation $(\mathrm{Na}$ or $\mathrm{Ba}$ ) and with $P n$. It turns out that the smallest number of electrons is transferred to the $\mathrm{Ti}_{2} \mathrm{Pn}_{2} \mathrm{O}$ layer in $\mathrm{BaTi}_{2} \mathrm{Bi}_{2} \mathrm{O}$, the compound with no density wave phase and the highest superconducting $\mathrm{T}_{c}$.

There are a number of questions that should be addressed in future studies of pnictide oxide superconductors. The experimental verification and the theoretical understanding of the nature of the density wave phase is crucial to understand the competition and mutual interaction of this phase with the superconducting state. The solid solution $\mathrm{BaTi}_{2}\left(\mathrm{Sb}_{1-x} \mathrm{Bi}_{x}\right)_{2} \mathrm{O}$ shows superconductivity only for small and 
large values of $\mathrm{x}$. The reason for the missing superconducting state around $\mathrm{x}=0.5$ has yet to be explored. The effects of electron doping, if achievable, on the density wave and superconducting states is of interest since it could help to understand the role of the electron density in the $\mathrm{Ti}_{2} \mathrm{Pn}_{2} \mathrm{O}$ layers. The Ti-based pnictide oxides are an interesting class of layered compounds and future work will certainly contribute to a deeper understanding of superconductivity and density wave instabilities and how those states interact with one another.

\section{Acknowledgments}

The authors gratefully acknowledge support from the T.L.L. Temple Foundation, the John J. and Rebecca Moores Endowment, the State of Texas through the Texas Center for Superconductivity at the University of Houston, the US Air Force Office of Scientific Research (FA 9550-09-1-0656), the National Science Foundation (CHE0616805), and the R. A. Welch Foundation (E-1297).

\section{References}

1. C. W. Chu et al., in Novel Superconductivity, edited by S. A. Wolf and V. Z. Kresin (Plenum Press, New York, 1987), p. 581.

2. C. W. Chu, in 50 Years of Bardeen, Cooper and Schrieffer, edited by L. N. Cooper and D. Feldman (World Scientific, Singapore, 2011), Chap. 16, p. 391.

3. H. Hosono, J. Phys. Soc. Jpn., Suppl. C 77, 1 (2008).

4. K. Ishida, Y. Nakai, and H. Hosono, J. Phys. Soc. Jpn. 78, 062001 (2009).

5. J. Paglione and R. L. Greene, Nature Physics 6, 645 (2010).

6. G. R. Stewart, Rev. Mod. Phys. 83, 1589 (2011).

7. I. I. Mazin and J. Schmalian, Physica C 469, 614 (2009).

8. M. D. Lumsden and A. D. Christianson, J. Phys.: Condens. Matter 22, 203203 (2010).

9. M. Gooch et al., Phys. Rev. B 79, 104504 (2009).

10. J. Maiwald, H. S. Jeevan, and P. Gegenwart, Phys. Rev. B 85, 024511 (2012).

11. S. Arsenijević et al., Phys. Rev. B 87, 224508 (2013).

12. J. H. Tapp et al., Phys. Rev. B 78, 060505(R) (2008).

13. Z. Ren et al., Phys. Rev. Lett. 102, 137002 (2009).

14. C. W. Chu and B. Lorenz, Physica C 469, 385 (2009).

15. A. Adam and H.-U. Schuster, Z. Anorg. Allg. Chem. 584, 150 (1990).

16. T. C. Ozawa and S. M. Kauzlarich, Sci. Technol. Adv. Mater. 9, 033003 (2008).

17. D. Johrendt, H. Hosono, R.-D. Hoffmann, and R. Pottgen, Z, Kristallogr. 226, 435 (2011).

18. S. L. Brock and S. M. Kauzlarich, Comments Inorg. Chem. 17, 213 (1995).

19. T. Yajima et al., J. Phys. Soc. Jpn. 81, 103706 (2012).

20. P. Doan et al., J. Am. Chem. Soc. 134, 16520 (2012).

21. E. A. Axtell, T. Ozawa, S. M. Kauzlarich, and R. R. P. Singh, J. Solid State Chem. 134, 423 (1997).

22. T. C. Ozawa, S. M. Kauzlarich, M. Bieringer, and J. E. Greedan, Chem. Mater. 13, 1804 (2001).

23. R. H. Liu et al., Phys. Rev. B 80, 144516 (2009).

24. T. C. Ozawa and S. M. Kauzlarich, J. Cryst. Growth 265, 571 (2004).

25. Y. G. Shi et al., Phys. Rev. B 88, 144513 (2013). 
26. X. F. Wang et al., J. Phys.: Condens. Matter 22, 075702 (2010).

27. U. Pachmayr and D. Johrendt, Solid State Sciences 28, 31 (2014).

28. F. von Rohr, R. Nesper, and A. Schilling, Phys. Rev. B 89, 094505 (2014).

29. H.-F. Zhai et al., Phys. Rev. B 87, 100502(R) (2013).

30. Y. Nozaki et al., Phys. Rev. B 88, 214506 (2013).

31. T. Yajima et al., J. Phys. Soc. Jpn. 82, 033705 (2013).

32. K. Nakano et al., J. Phys. Soc. Jpn. 82, 074707 (2013).

33. T. Yajima et al., J. Phys. Soc. Jpn. 82, 013703 (2013).

34. W. E. Pickett, Phys. Rev. B 58, 4335 (1998).

35. F. von Rohr et al., Phys. Rev. B 88, 140501(R) (2013).

36. B. T. Matthias and J. K. Hulm, Phys. Rev. 87, 799 (1952).

37. J. S. Shier and D. M. Ginsberg, Phys. Rev. 147, 384 (1966).

38. D. J. Singh, NJP 14, 123003 (2012).

39. A. Subedi, Phys. Rev. B 87, 054506 (2013).

40. M. Gooch et al., Phys. Rev. B 88, 064510 (2013).

41. H. Padamsee, J. E. Neighbor, and C. A. Shiffman, J. Low. Temp. Phys. 12, 387 (1973).

42. S. Kitagawa et al., Phys. Rev. B 87, 060510(R) (2013).

43. B. Lorenz and C. W. Chu, in Frontiers in superconducting materials, edited by A. V. Narlikar (Springer, Berlin, Heidelberg, New York, 2005).

44. M. Gooch et al., Supercond. Sci. Technol. 26, 125011 (2013).

45. B. Lorenz et al., Phys. Rev. B 78, 012505 (2008).

46. M. Gooch et al., Phys. Rev. B 78, 180508(R) (2008).

47. T. C. Ozawa, R. Pantoja, E. A. Axtell, and S. M. Kauzlarich, J. Solid State Chem. 153, 275 (2000).

48. J. Lynn, private communication. (unpublished).

49. Y. Huang et al., Phys. Rev. B 87, 100507(R) (2013).

50. F. F. de Biani, P. Alemany, and E. Canadell, Inorg. Chem. 37, 5807 (1998).

51. X.-W. Yan and Z.-Y. Lu, J. Phys.: Condens. Matter 25, 365501 (2013).

52. X.-L. Yu et al., preprint, arXiv:cond-mat/1402.4723 (unpublished). (unpublished).

53. D. V. Suetin and A. L. Ivanovskii, J. Alloys Comp. 564, 117 (2013).

54. D. V. Suetin and A. L. Ivanovskii, JETP Letters 97, 220 (2013). 